\title{
Research Progress on Interlaminar Failure Behavior of Fiber Metal Laminates
}

\author{
Yizhe Chen $\mathbb{D}^{1,2}$ Yichun Wang, ${ }^{1,3}$ and Hui Wang $\mathbb{D}^{1,2}$ \\ ${ }^{1}$ Hubei Key Laboratory of Advanced Technology for Automotive Components, Wuhan University of Technology, Wuhan 430070, \\ China \\ ${ }^{2}$ Hubei Collaborative Innovation Center for Automotive Components Technology, Wuhan 430070, China \\ ${ }^{3}$ Hubei Engineering Research Center for Green \& Precision Material Forming, Wuhan 430070, China \\ Correspondence should be addressed to Hui Wang; huiwang@whut.edu.cn
}

Received 31 May 2019; Revised 29 January 2020; Accepted 11 February 2020; Published 9 March 2020

Academic Editor: Sagar Roy

Copyright (C) 2020 Yizhe Chen et al. This is an open access article distributed under the Creative Commons Attribution License, which permits unrestricted use, distribution, and reproduction in any medium, provided the original work is properly cited.

\begin{abstract}
Fiber metal laminate (FML) is a kind of lightweight material with excellent mechanical properties combining advantages of metal laminates and fiber reinforced composites. It has been widely used in the aerospace and transportation fields and is especially used as structural material such as aircraft skins, wings, and tails. However, under complex service conditions, interlaminar failure in FMLs greatly reduced mechanical properties of the material, even leading to serious economic and safety disasters. The failure and destruction of important structural parts of aircraft and other manned transportation vehicles are extremely unsafe for people. Therefore, it is of great significance to summarize the interlaminar failure behavior of FMLs and find ways to avoid these defects. This review paper is a collection of various researches done by many groups, which systematically discuss the interlaminar failure behaviors and their control methods of FMLs. The application status of several common FMLs in aircraft structures was given. The common interlaminar failure modes of FMLs and the testing and evaluation methods of interlaminar properties were stated. The failure mechanisms and the corresponding control methods were analyzed. Finally, the future developments of FMLs were also discussed by the authors. Through this review article, readers can obtain new research progress about the control method, the mechanism and future development on the failure behavior of FMLs in a more efficient way.
\end{abstract}

\section{Introduction}

In recent years, many countries including the United States, Japan, Germany, and China have promulgated related policies on energy conservation and emission reduction. As "energy conservation and emission reduction" [1-3] has become a popular topic, lightweight materials have been widely applied to many important fields such as aerospace, automobile transportation, architecture, and pipeline transportation $[4,5]$. Lightweight aircraft and automotive structures can not only greatly reduce fuel consumption and environmental pollution but also effectively improve the service life of key components [6, 7]. Among them, FML, which was made of metal plates and fiber composite materials through hot pressing and curing, has attracted the attention of researchers for its excellent mechanical properties and weight reduction effect $[4,8-15]$, as shown in Figure 1.

In the 1980s, aramid fiber reinforced aluminum alloy laminates (ARALL) $[16,17]$ were first implemented as wing skin of Fokker Aircraft's F-27. Subsequently, Douglas Company of the United States began to use the ARALL laminate to manufacture the cargo door of C-17 large military transport helicopter, and the weight was reduced by $26 \%$. The anticorrosion performance, impact resistance, and fatigue resistance of the laminate were stable during the service time $[18,19]$. However, due to the poor interlaminar shear strength of the ARALL, it can only be applied to the flat structure or the single curved surface with small curvature of the aircraft [18]. In the 1990s, glass reinforced aluminum 


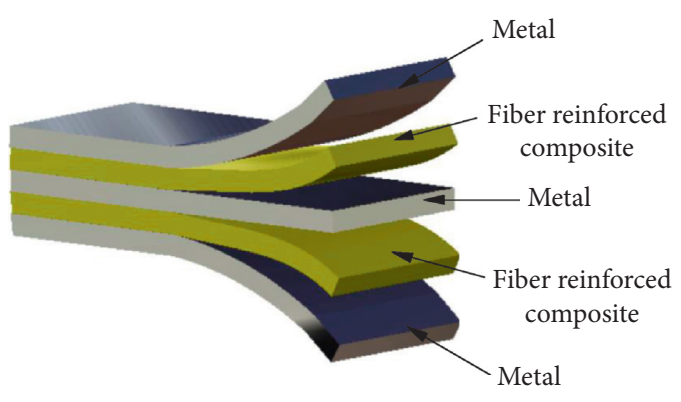

Figure 1: Composition of FML.

laminates (GLARE) started to be used in some big aircrafts because of the excellent properties [20-25]. For the first time, the bulkhead on the rear of the A340 passenger aircraft was made of GLARE laminates and three radial crack locking devices were also made of GLARE laminates [26]. Then, the A380 aircraft also used a large number of GLARE laminates throughout the upper fuselage skin, fairing, trailing edge, upper fuselage wall, and upper wall [26-29]. At the same time, American Boeing Aircraft Corporation used GLARE laminates to make cabin floors for Boeing 757 and Boeing 777 [30]. The application of titanium/graphite hybrid laminates (TIGR) in aircraft also began in the 1990s [31]. To solve the problems of high temperature resistance and fatigue resistance of supersonic aircraft component materials [32-34], TIGR laminates were installed on the wing and fuselage skins of the Boeing 787 [35-38] and the hatches of the V-22 engine [39]. In recent years, some scholars have replaced the 2024-T3 aluminum alloy used in traditional GLARE laminates with a new aluminum-lithium alloy as a metal substrate, and they have developed new glass fiberaluminum-lithium alloy superhybrid composite laminates (NFMLs), which can increase the stiffness by $8 \%-12 \%$ and significantly improve the fatigue property of the material [40-42].

However, there are still many problems to be solved in the forming and using process of FMLs. Under shear stress, bending stress, impact stress, and axial stress, the strength and stiffness of the FMLs will be significantly reduced and cause interlaminar failure behavior such as debonding and delamination, which will cause the overall failure of the material and eventually cause serious damage. Therefore, analyzing the failure mechanism and control methods of FMLs can control the failure of materials to some extent. However, in general, there are not enough articles systematically introducing the failure behavior, evaluation method of interlaminar property, and failure mechanism and control methods of FMLs. Therefore, it is very necessary to summarize the mentioned subjects of FMLs systematically.

In this review article, the application status of several common FMLs in aircraft structures was given. The common interlaminar failure modes of FMLs and the testing and evaluation methods of interlaminar properties were stated. The failure mechanisms and the corresponding control methods were analyzed. Finally, the future developments of FMLs were also discussed by the authors.

\section{Main Failure Mode and Control Method of FMLs}

The failure of FMLs is mainly caused by the accumulation of damage. The failure modes mainly include fiber-resin matrix debonding, fiber fracture, resin matrix crack propagation, metal layer/fiber layer interlaminar delamination, and metal fracture failure [43]. When materials are used in aircraft or automobile structures, they are often subjected to complex stress conditions such as axial stress, bending stress, shear stress, and impact stress. For example, when extrusion occurs between parts or temperature changes greatly, FMLs are often subjected to tensile stress or compressive stress. When an airplane or a car is strongly impacted, the structure often needs to bear huge shear stress and bending stress. When the aircraft encounters bird strikes or drop of tools, the aircraft structure needs to bear great high-speed impact stress [44, 45]. Several common stresses are shown in Figure 2. Depending on the applied stress, the main failure modes of the FML have a more complex form of expression. The common failure modes of FMLs and their control methods are summarized below.

2.1. Failure and Control Method under Shear Stress. The interlaminar shear strength refers to the bonding strength between fibers and the matrix resin in FML [46]. The interlaminar shear strength of composites is closely related to the interlaminar bonding quality of materials $[47,48]$. When the shear stress is greater than the maximum interlaminar shear stress, the composite material will be damaged or fail $[49,50]$.

The interface of the FML is extremely sensitive to the shear stress, and one of the most typical failure mechanisms of laminar composites is debonding delamination. Liu [51] studied the interlaminar shear failure behavior of GLARE laminates and found that the effective interlaminar shear failure was the debonding delamination failure near the neutral layer, which was manifested by shear misalignment, end opening, or local shear debonding, as shown in Figure 3. In the experiment, if the span-to-thickness ratio was below 8 , the pure shear failure occurred. If the span-to-thickness ratio was greater than 10 , the failure mode was bending failure $[26,51,52]$.

The interlaminar shear strength of the FML can be effectively improved by surface treatment of the metal and adjustment of different layer design. Ti/CF/PMR polyimide superhybrid laminate is a high-temperature-resistant FML that uses $\mathrm{CF} / \mathrm{PMR}$ polyimide as a prepreg. A study of Ti/CF/ PMR polyimide superhybrid laminates by $\mathrm{Hu}$ found that the treated laminates had higher interlaminar shear strength [53]. Since the fiber/resin interface and the metal/resin interface were closely related, the interface between the surface treated metal and the resin had excellent adhesion. He et al. [54] found that the samples after anodizing, annealing, and primer treatment were superior to the original samples in terms of shear strength and specific elongation. Goushegir et al. [55] tested on aluminum-based laminates after 


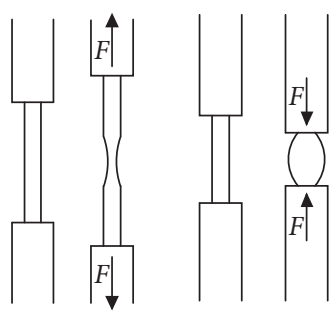

(a)

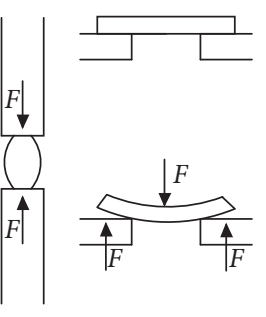

(b)

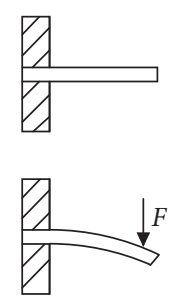

(c)

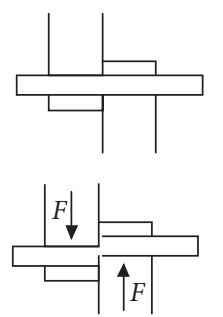

(d)

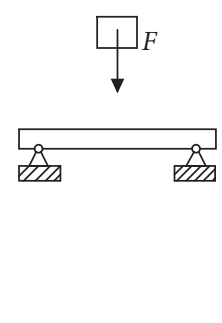

(e)

Figure 2: Five common stress diagrams. (a) Tensile stress, (b) compressive stress, (c) bending stress, (d) shear stress, and (e) impact stress.

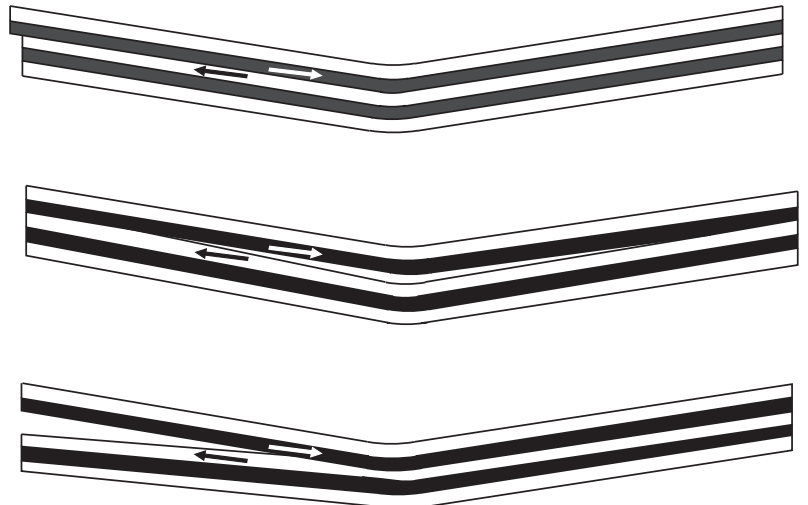

FIGURE 3: Failure of FMLs under pure shear stress [51].

different surface treatments, such as mechanical grinding, sand blasting, acid pickling, conversion coating, and electrochemical pretreatment. The results showed that all surface pretreatments increased the interlaminar shear strength of FMLs, and phosphoric acid anodizing-primer specimens demonstrated the highest increase in shear strength.

The interlaminar shear test of laminates with different ply angles showed that the interlaminar shear strength of FMLs with unidirectional ply angle was the highest. It was confirmed by Hu's test that Ti/CF/PMR polyimide superhybrid laminate with unidirectional ply angle had the highest interlaminar shear strength, and the $\pm 45^{\circ}$ laminate had a lower interlaminar shear strength [56].

2.2. Failure and Control Method under Bending Stress. The bending property can reflect the bending failure behavior and damage mechanism of the laminate under stress. Under the bending stress, the laminate is subjected to both normal stress and shear stress. Therefore, the failure mode is more complicated, and the changes in structure and layer design will affect the failure behavior of the material $[48,57]$.

Under the bending stress, the failure of the FML mainly manifests as the failure of fiber layer and metal layer under the normal stress, interlaminar shear failure, and the mixed failure under normal stress and shear stress [58], as shown in Figure 4. Yurgartis and Sternstein [59] discovered that the shear stress and bending stress on the transverse section of GLARE laminate worked together during bending deformation, resulting in the simultaneous existence of normal stress and shear stress.
The interlaminar failure behavior of FMLs was considerably affected by ply angle. The longitudinal fibers in FMLs increase the bending stiffness and strength [60]. The control of bending failure defects can be realized by using unidirectional FMLs. Hu concluded from bending test curves that the laminates would have different flexural strength when different layers were used. According to the metal volume fraction (MVF) theory [37], the flexural strength of the Ti/CF/PMR polyimide superhybrid laminate was lower than that of the unidirectional laminate due to the introduction of the metal layer. Comparing the flexural strength of Ti/CF/PMR polyimide superhybrid laminates using different ply angles, it could be found that FMLs with unidirectional ply angle have better flexural strength along the fiber direction [61].

In addition, good interlaminar bonding strength can also improve failure behavior under bending stress. Xu et al. [62] found that there were two ways to improve the bonding strength between the metal layer and the fiber layer. The first method was to make surface treatment on the metal before preparation to remove dirt on the metal surface and loosen the surface oxide film to increase surface roughness. The second method was to use adhesive [63-65] to improve the bond strength between metal and prepreg. Hu et al. [66] found that the bending property of the carbon fiber reinforced PMR polyimide FMLs was significantly improved after the titanium surface was treated by anodic oxidation method.

Khalili et al. [67] studied basalt FMLs and found that the presence of steel layers had a good effect on improving the bending strength and tensile strength of FMLs.

2.3. Failure and Control Method under Axial Stress. Axial stress can be further divided into tensile stress and compressive stress. Under the two different stresses, FML will have different failure behaviors. Under the longitudinal tensile stress, failure behaviors of the laminate were shown as resin matrix cracking, fiber breakage, fiber/resin interfacial debonding, and so forth $[68,69]$. Sharma et al. [70] prepared FML with metal layers placed at different locations along the thickness and evaluated its tensile response through tensile testing. They found that the failure modes of unidirectional laminates include fiber breakage, metal breakage, and necking. However, when it came to orthogonal laminate, mixed failure including fiber layer delamination, fiber breakage, and metal breakage may occur. 


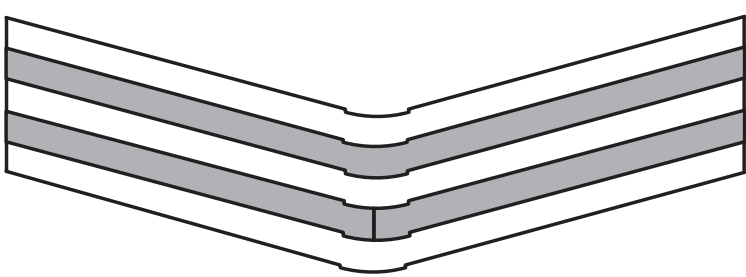

(a)

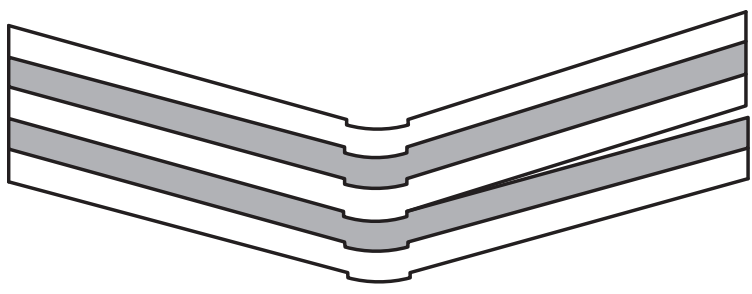

(c)

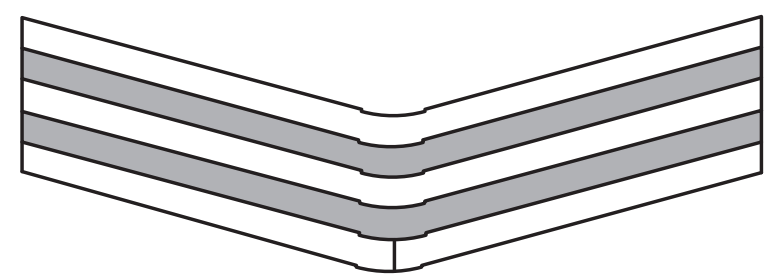

(b)

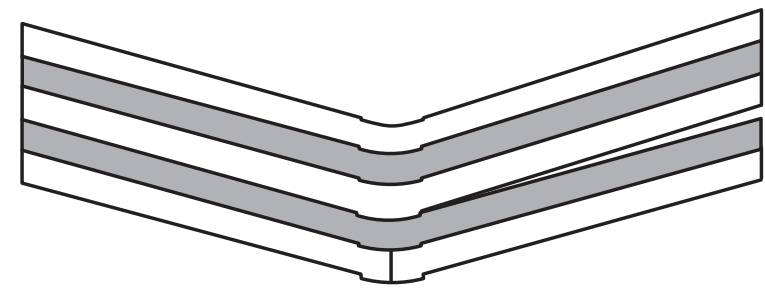

(d)

Figure 4: Failure of FML under bending stress [58]. (a) Fiber layer failure; (b) metal layer failure; (c) interlaminar shear failure; (d) mixed damage.

Under the compressive stress, the test found that FMLs would buckle. First, the metal layer buckled in the same direction. Then, under the shear stress, the resin deformed, and the metal/fiber layer interface began to delaminate [71, 72]. After buckling, local deformation would cause matrix interlaminar and intraply failure forms such as matrix failure, fiber failure, delamination, and debonding, as shown in Figure 5.

Because the fibers have different properties in different angles, this leads to the phenomenon of anisotropy. Due to the anisotropy of fibers, FMLs also have different mechanical properties in different directions [70, 74]. Therefore, the tensile properties of the FML can be improved by means of two-way reinforcement. In the study of the tensile properties of the GLARE laminate, some scholars concluded that, due to the strength difference between fiber and metal in the transverse and longitudinal directions, the tensile property would be reduced in both directions. The decrease of tensile property would aggravate the possibility of tensile failure. However, when the glass fiber was used for bidirectional reinforcement, the tensile property of the GLARE laminate in both the transverse and longitudinal directions would increase, and the degree of improvement was related to the fiber content $[75,76]$.

With the increase of metal volume fraction, the elastic modulus of the laminate increases and the tangent modulus decreases. Meanwhile, the tensile strength of the material decreases with the increase of metal volume fraction. Therefore, it is also possible to effectively control the tensile defects by changing the volume fraction of the metal [77].

Thermal cycling can also improve the tensile property of FMLs. Khalili et al. studied the effect of thermal cycling on the tensile property of FMLs. They found that the tensile strength of the material could be improved whether it was subjected to low- or high-temperature cycling [78]. Their results revealed that more-layered FML was more affected by the thermal cycles in comparison with lesslayered FML.
2.4. Failure and Control Method under Impact Stress. Besides the properties of high strength and high stiffness, FMLs still need to have good impact resistance. Impact damage is an important form of damage failure in aircraft and automotive structural parts [79]. It consists of lowvelocity impact and high-velocity impact.

Since most composite materials are brittle, they can only absorb energy during the elastic deformation. Therefore, under the condition of no plastic deformation, the low-velocity impact damage is concealed, but it may cause the overall failure of the structural members as the damage accumulates [80]. Under the low-velocity impact stress, the failure modes of FMLs include metal layer cracking, fiber layer fracture, and interfacial debonding $[81,82]$. The interfacial debonding under the impact stress generally includes debonding between different fiber layers and debonding between the fiber layer and the metal layer, as shown in Figure 6.

High-velocity impact can lead to complete failure of the FML and even lead to penetration $[83,84]$. Chen et al. found that as the impact velocity increased, the damage area of the GLARE laminate gradually increased. Under ballistic impact, GLARE laminates mainly release absorbed impact energy through plastic deformation, metal cracking, debonding, and fiber breakage. The way GLARE laminates are damaged is related to the initial velocity of the bullet, including metal cracking, brittle fracture of the fibers, and damaged areas. At the same time, the failure mode of GLARE laminates under impact stress is also significantly affected by constraints. For example, the ballistic limit velocity of the GLARE laminates impacted at the corner of the plate was found to be much less than that impacted at the middle location of the plate [85].

The impact resistance property of the FML is related to the thickness of the laminate, the fiber diameter, and the ply angle. In a comprehensive study of the low-velocity impact response of GLARE laminates, Morinière et al. concluded that as the number of layers increased, the metal volume fraction decreased gradually, and the specific absorption of the 


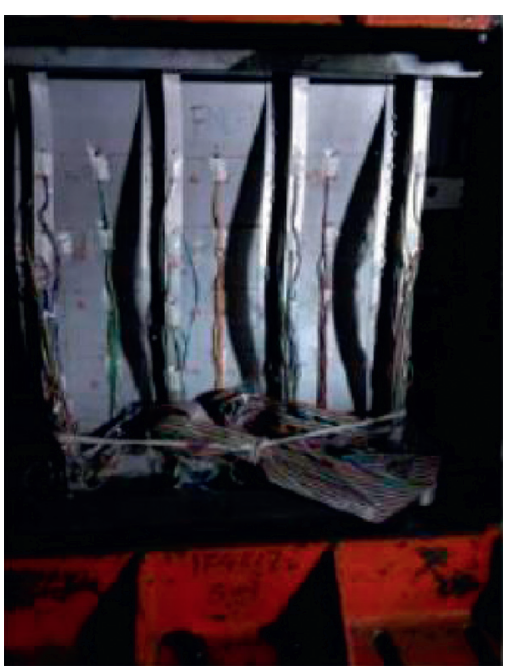

(a)

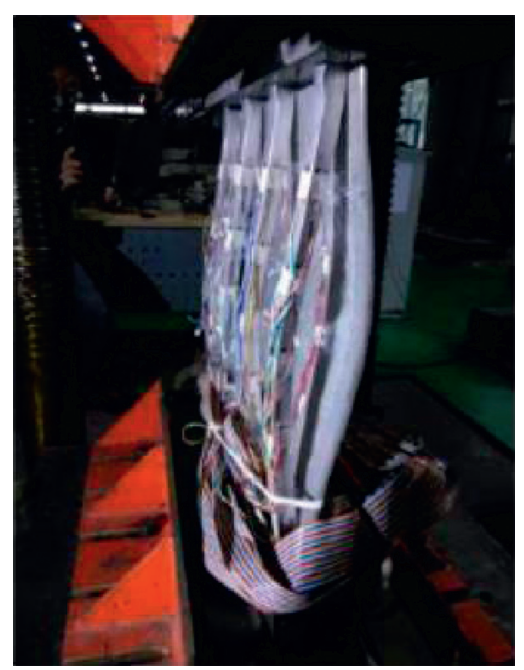

(b)

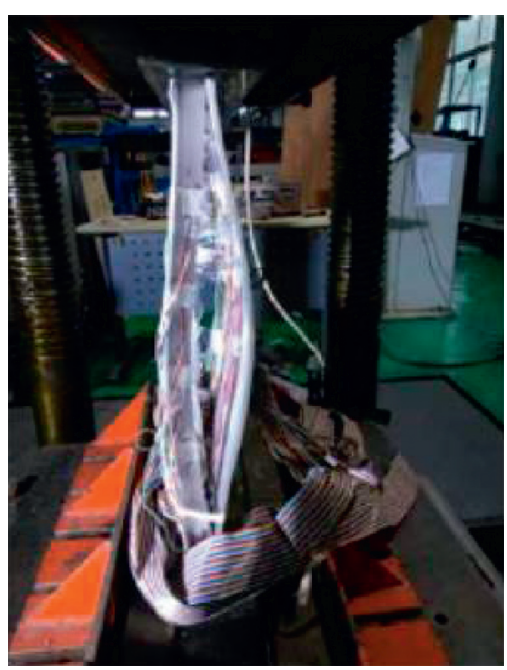

(c)

FIGURE 5: Destruction of fiber metal materials under axial compression stress [73]. (a) Skin buckling, (b) long buckling, and (c) overall instability of the siding.

laminates was gradually increased [87]. It indicates that the fiber layer plays an important role in improving the specific absorption energy of the laminate [56]. However, due to the different structures of the laminate, the thickness cannot be adjusted at will. Therefore, changing the ply angle is still the first choice to control the impact failure defects $[88,89]$.

The treatment of the metal surface also improves the impact resistance of the material. Prashantha Kumar concluded in the impact test on the magnesium alloy fiber composite laminates that the impact resistance of the material was effectively improved after the surface treatment of the metal layer [90]. Mehr's team [45] also found that the combination of forest product laboratory etching (FPL) or sulfuric acid anodizing (SAA) treatment after sand blasting had a positive impact on the low-velocity impact behavior of FML.

Bahari-Sambran et al. [60] studied the effect of adding surface-modified nanoclay on the mechanical behavior of basalt fiber-epoxy resin/aluminum laminate composites. They found that the addition of clay gave FMLs higher impact strength. This may be due to the improved interlaminar property.

\section{Method for Evaluating Interlaminar Properties of FMLs}

According to the above analysis, interlaminar failure is the most serious failure of FMLs. The interlaminar properties of FMLs are closely related to the bonding interface between resin and fiber or resin and metal. Therefore, the accurate evaluation and accurate test of the failure behaviors of FMLs are of great importance, as can be seen in Table 1 .

3.1. Short-Beam Method. The short-beam method (SBS) is simple to operate and it can save material. It can be used not only as a primary means to evaluate the interlaminar shear property of FMLs but also to evaluate interlaminar fracture toughness and to test bending property by using three-point bending SBS [48].

At present, a variety of methods have been developed to evaluate the interlaminar shear property of composites $[49,52,91,92]$, and the SBS is one of the most common evaluation methods $[93,94]$. The main short-beam shear test standard is ASTM-D2344, which is primarily for high modulus fiber reinforced composites. Liu [51] used the GLARE laminate to compare the superiority of the doublebeam method with the SBS and made the improved SBS more suitable for the evaluation of interlaminar shear property. As shown in Figure 7, the three-point bending SBS was also used to study the GLARE interlaminar failure behavior [95]. Reyes and Cantwell also used three-point bending SBS in the test to study the interlaminar shear property of FMLs [8].

The SBS can also be used to evaluate the fracture toughness between layers. Interlaminar fracture of FMLs usually starts at the interface. When the stress in the thickness direction exceeds its strength limit, delamination fracture will be induced on the laminate interface. Since the crack propagation of the delamination fracture depends on the interlaminar fracture toughness of the laminate, the researchers have tested and evaluated the interlaminar fracture toughness of various bimaterial interfaces. Under different stress, the interlaminar fracture toughness can be measured by the following three methods: three-point bending SBS, four-point bending SBS, and double cantilever beam method (DCB). When the above three evaluation methods are used, different stresses need to be applied to different parts of the sample, respectively. The three-point or four-point bending SBS is mainly to obtain the critical fracture toughness of the interlaminar failure under the shear stress, as shown in Figure 8.

3.2. Cantilever Beam Method. The cantilever beam method is often divided into single cantilever beam method (SCB) and $\mathrm{DCB}$, which is mainly used to evaluate the interlaminar 


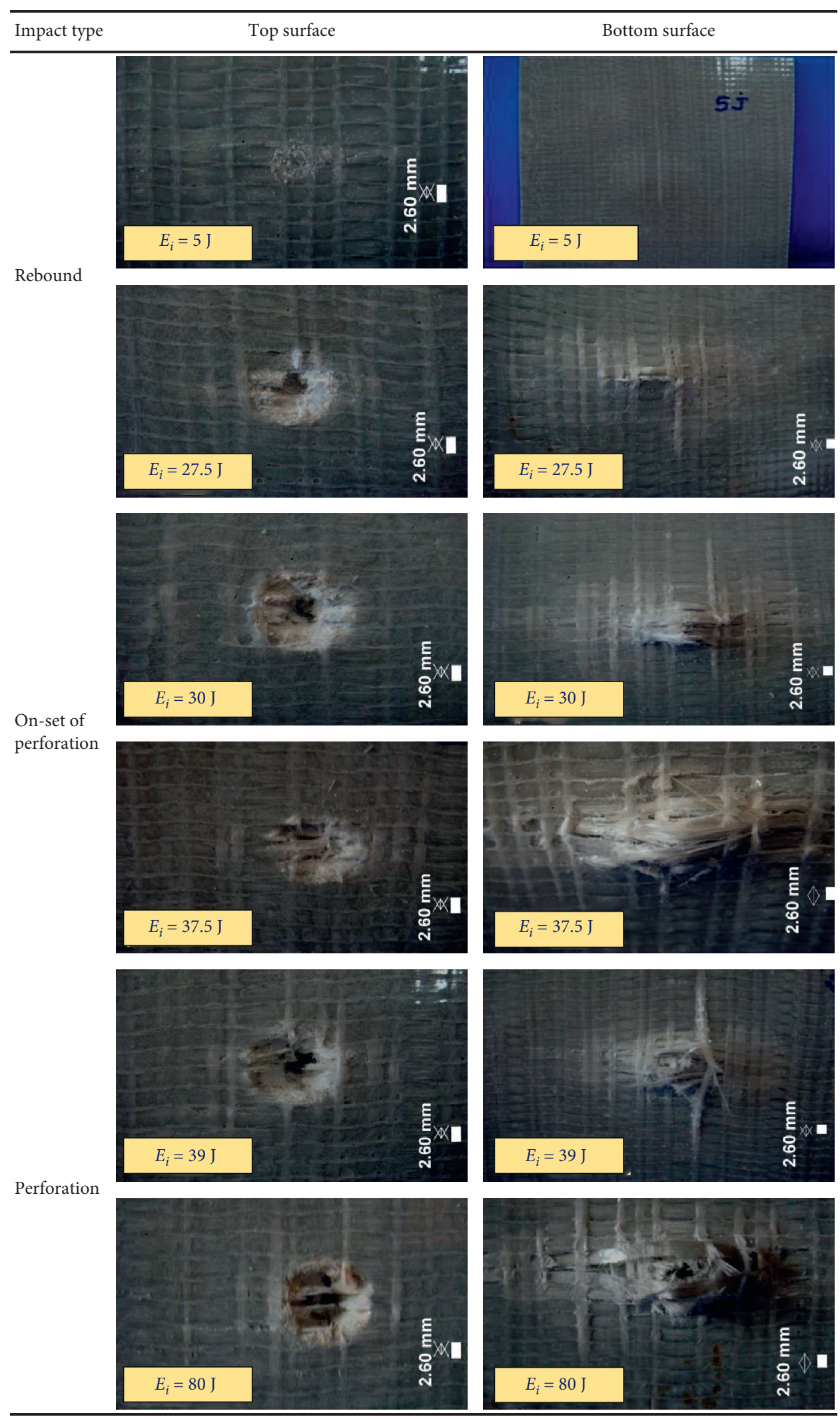

FiguRE 6: Damage view of unidirectional composites subjected to impact stress [86].

fracture toughness of composite laminates. Interlaminar fracture toughness is one of the important criteria for evaluating the interlaminar adhesion property of FMLs.
The SCB test is a simple and effective method for evaluating the fracture toughness of laminates [96-100], as shown in Figure 9. Meanwhile, DCB is usually used to measure the 
TABLE 1: Method for evaluating interlaminar property of FMLs.

\begin{tabular}{lcl}
$\begin{array}{l}\text { Types of } \\
\text { methods }\end{array}$ & $\begin{array}{c}\text { Common } \\
\text { applications }\end{array}$ \\
\hline & Evaluate \\
& interlaminar \\
& shear \\
& property; \\
Short- & Evaluate \\
beam & Schematic diagram \\
method & interlaminar \\
(SBS) & fracture \\
& toughness; \\
& Test bending \\
& property. & \\
&
\end{tabular}

Evaluate the
$\begin{array}{ll}\text { Cantilever } \\ \text { interlaminar } \\ \text { fracture } \\ \text { toughness }\end{array}$

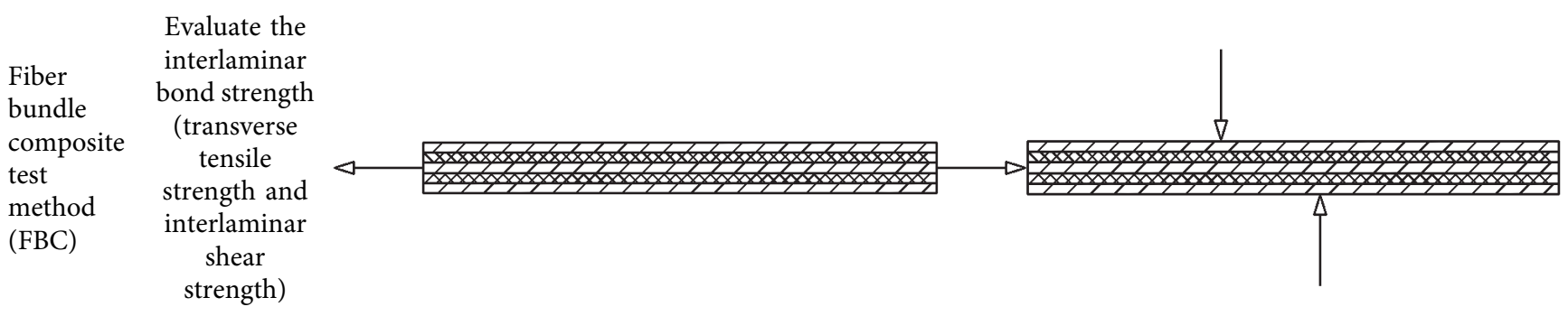

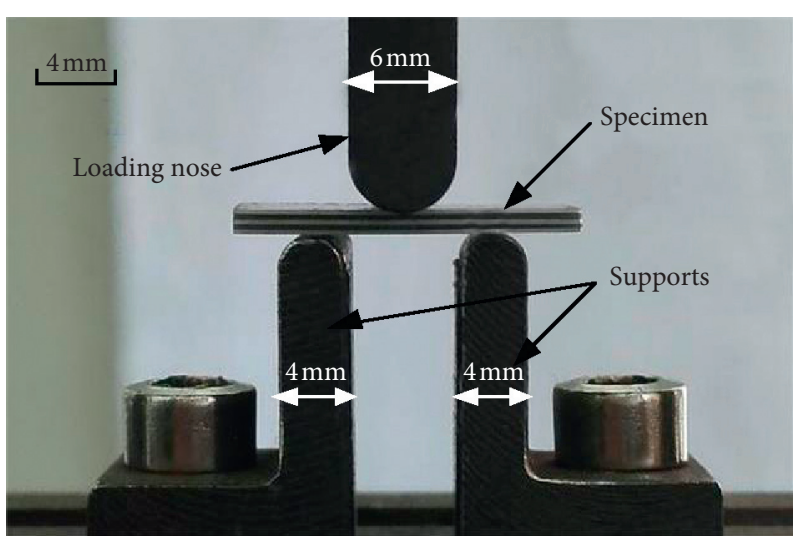

FIgURE 7: Short-beam method shear experiment [51].

critical fracture toughness of interlaminar failure under normal stress [38, 101, 102], as shown in Figure 10.

3.3. Fiber Bundle Composite Test Method. The interlaminar properties of the FML are closely related to the bonding strength of the interface. The interlaminar state of the FML not only affects the fatigue properties of the laminate but also determines the failure behavior. Xu [58] found that the higher the bonding strength of the GLARE laminate interface, the lower the fatigue crack growth rate and the better the fatigue performance of the laminate. When the interlaminar bonding strength is high, the delamination failure occurs inside the fiber layer, and the width of the delamination area is small. When the interlaminar bonding strength is low, the delamination failure form is mixed failure including the failure at the metal/fiber layer interface and the failure of the fiber layer, and the width of the delamination area is large. It can be proven by the above evaluation analysis that the interlaminar bonding strength has a huge influence on the interlaminar properties of the composite material.

In recent years, researchers have begun to use fiber bundle composite $(\mathrm{FBC})$ tests to evaluate the interlaminar bonding strength between fibers and matrix in fiber reinforced composites, as shown in Figure 11. The FBC test can simulate the stress situation when the unidirectional laminate fails, and it is convenient to test and the test results are more concentrated. The FBC test is mainly divided into fiber bundle tensile test, fiber bundle shear test, and fiber bundle pull-shear coupling experiment. Among the fiber bundle tensile tests, Ageorges et al. studied the bonding property between surfacemodified carbon fibers and epoxy resins [104]. Zham et al. first proposed a model for testing the shear strength of fiber bundles and substrates by tensile tests [105]. Qi et al. first proposed a $45^{\circ}$ oblique fiber bundle tensile test piece and found that the fracture section was also at the interface between the fiber bundle and the matrix. The tensile-shear coupling effect can be achieved at the interface [92].

The evaluation of interlaminar properties fundamentally characterizes some properties of FMLs and provides guidance for the analysis of interlaminar failure behavior of FMLs. 


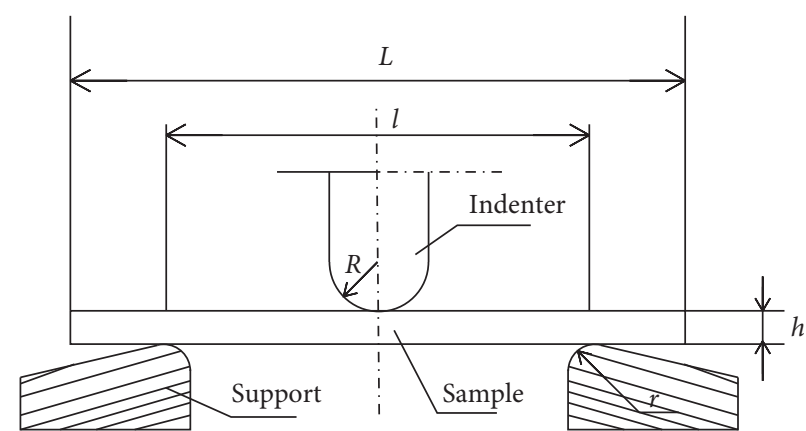

(a)

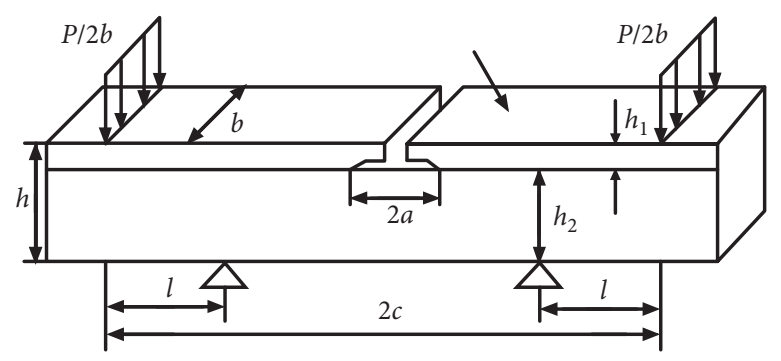

(b)

Figure 8: Common types of SBS [38]. (a) Three-point bending method. (b) Four-point bending method.

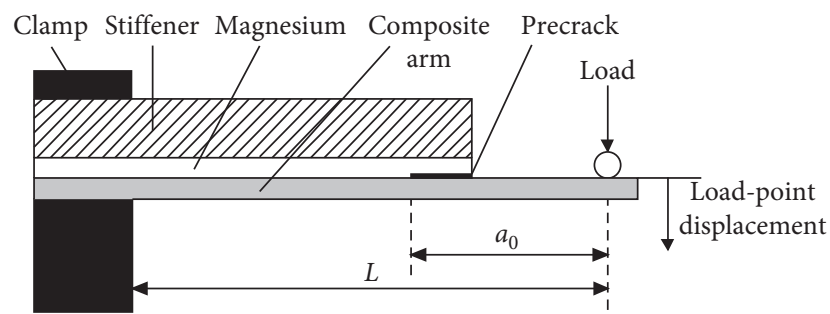

FIgURE 9: Schematic diagram of SCB test [103].

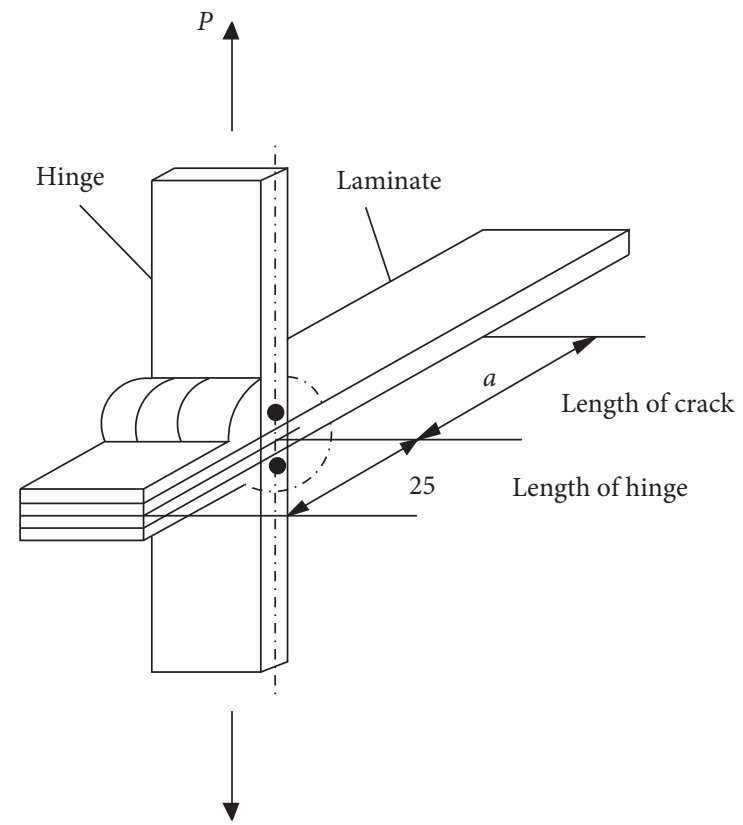

FIGURE 10: DCB method for measuring interlaminar fracture toughness [38].

\section{Mechanism Analysis of Interlaminar Failure}

From the mentioned research results, it can be seen that the failure behavior of FMLs has greatly damaged the material properties and even caused the material to be scrapped. This has seriously affected the service performance of FMLs as various structural parts. Therefore, it is very important to analyze and study the interlaminar failure mechanism of the
FMLs [46, 84, 107-111]. The main damage failure mode of composites is interlaminar failure, which refers to the separation between the fibers and the adjacent metal layers. This phenomenon mostly occurs in the vicinity of the openings, the thickness transition areas and free edges, and also stress concentration areas [112-114].

4.1. Mechanisms of Interlaminar Shear Failure. According to the SBS test principle, the interlaminar shear stress of the composite laminate near the neutral layer is the largest. When the shear stress on the laminate is greater than its ultimate shear stress, local debonding may occur. Debonding in the composite and metallic sections can further expand to entire delamination. The specific performance of the failure is the end opening of the intermediate metal layer and the fiber layer, local shear debonding, and shear misalignment.

The end opening is one of the typical pure shear failure modes. Liu [51] observed the microscopic appearance of the open shear surface and found that the resin matrix appeared to roll up and shrink. This was the interlaminar failure behavior caused by the interlaminar shear force. Since the interlaminar shear stress played a leading role in the condition that the composite layer and the metal layer were laid in the same angle, the specimen had a pure shear failure.

Local shear debonding often occurs in cross-ply laminate and angle-ply laminate, and the fiber-matrix debonding mechanism plays a key role in the failure behavior of nonunidirectional laminates. Under the shear stress, debonding between the single fiber and the resin matrix occurred in many places at first. Then, the number of debonded fibers increased and the matrix between the debonded fibers also began to crack. Finally, the shear delamination failure occurred. The initial failure of the cross-ply laminate under the interlaminar shear stress also originated from the debonding between the individual fibers and the resin matrix. Subsequently, the debonding surface between the fiber and the substrate was continuously increased, and the matrix between the debonded fibers also began to crack, eventually leading to interlaminar shear failure of the laminate, as shown in Figure 12. 


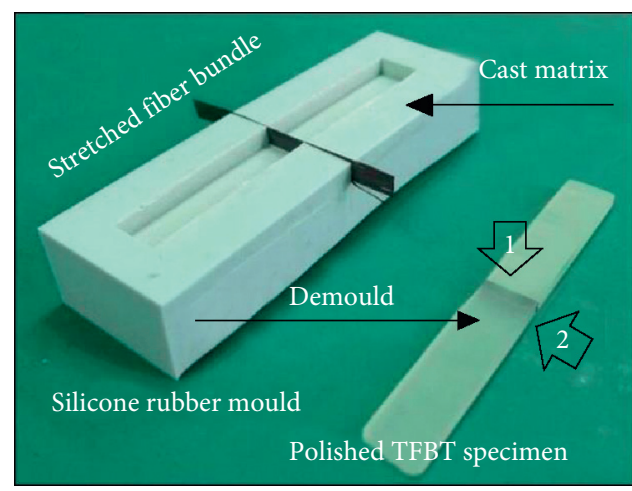

(a)

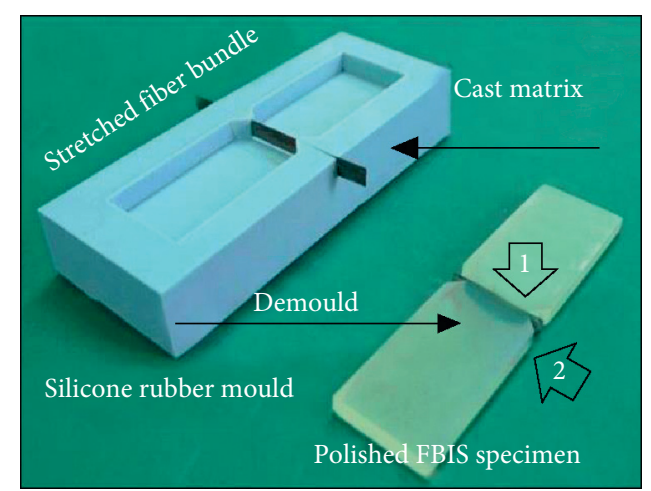

(b)

Figure 11: Preparation of TFBT and FBIS test pieces for fiber bundle test [106].

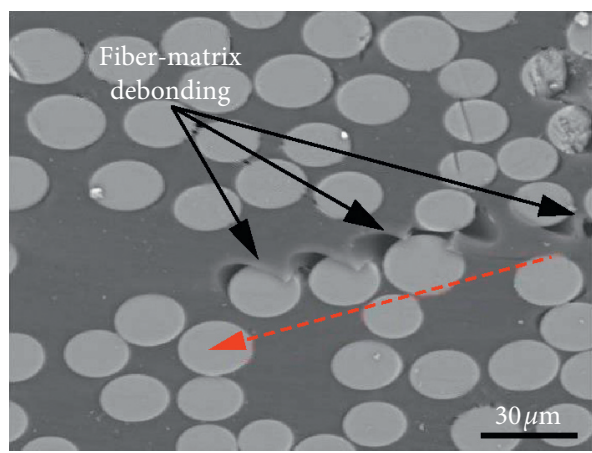

(a)

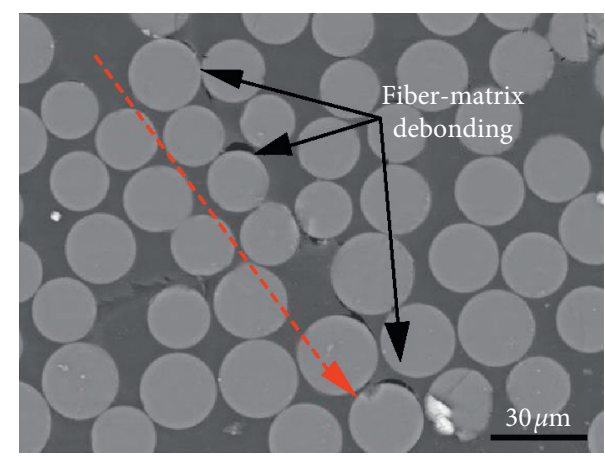

(b)

FIGURE 12: Debonding failure mechanism of short-beam fiber matrix, observed by SEM (FEI Quanta 200) [51]. (a) Angle-ply laminate; (b) cross-ply laminate.

4.2. Mechanisms of Interlaminar Bending Failure. When the FML is subjected to bending stress, the shear stress and the bending moment existing simultaneously on the transverse section work together, resulting in the simultaneous existence of the shear stress and the normal stress. The outside of the laminate is subjected to tensile stress, and the inner side is subjected to compressive stress. As the deflection increases, the laminate continues to bend and deform. When the bending deformation reaches the strain limit or the normal stress reaches the stress limit, the fiber layer or the metal layer may be broken, resulting in bending failure.

Different ply angles lead to different failure behaviors. Tao Gang studied the curved section of the GLARE laminate and the SEM images of the fiber/metal interface in three different ply angles [95]. With the increase of bending stress, the side of the unidirectional laminate near the stress was subjected to compressive stress. The metal layer began to yield and shrink, while the fiber layer remained elastically deformed. As the bending stress continued to increase, a large amount of fiber breakage occurred. When the bearing limit was reached, interlaminar delamination failure occurred in the metal/fiber layer. After studying the bending property of GLARE laminates, $\mathrm{Xu}$ [58] concluded that the difference between unidirectional laminates and cross-ply laminates was that, with the increasing of bending stress, the cross-ply laminates not only had damage in the $0^{\circ}$ layer but also included crack expansion in the $90^{\circ}$ layer, as shown in Figures 13 and 14. When the stress limit is reached, interlaminar delamination failure will occur. If the stress continues to increase, it will eventually lead to metal breakage. Ye et al. [115] analyzed the fiber reinforced composite material using multiscale modeling; it was found that crack firstly appeared in the $90^{\circ}$ layer. As the external load continues to increase, the crack accumulated along with the layer direction for $-45^{\circ}$ layer, $45^{\circ}$ layer, and $90^{\circ}$ layer.

Similarly, $\mathrm{Hu}$ [56] found a similar result when studying Ti/CF/PMR polyimide superhybrid laminates. Under the bending stress, the main failure modes of the specimen were delamination failure and local buckling failure, as shown in Figure 15.

4.3. Mechanisms of Delamination between Interfaces. In addition to the above two forms of failure defects, debonding is one of the most typical failure mechanisms for layered composites. Debonding occurs mostly between the metal and fiber layers [116]. As the damage degree intensifies and the fiber deforms along its length, the fiber will gradually be pulled out [117]. Interfacial debonding and fiber pull-out of 


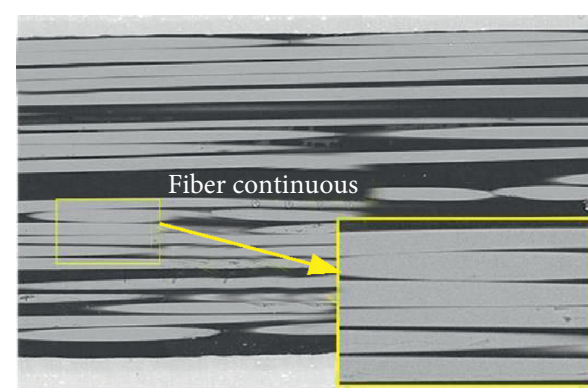

(a)

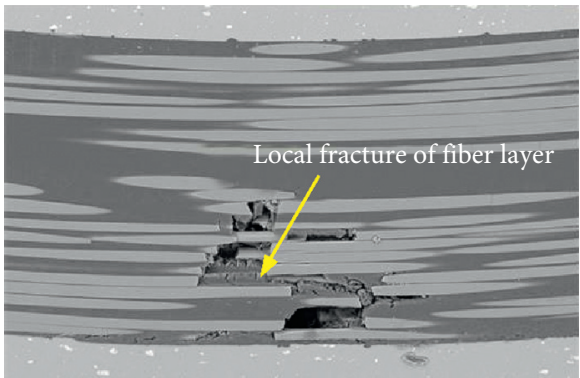

(c)

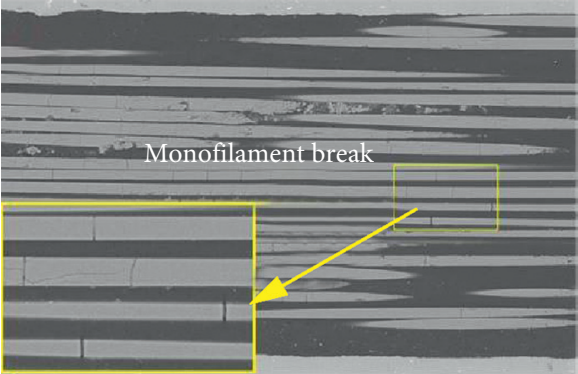

(b)

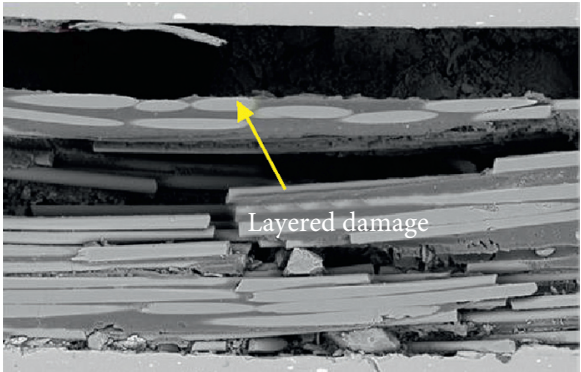

(d)

FIGURE 13: Microstructure of laminates in each stage of unidirectional laminate bending test observed by SEM (FEI Quanta 200) [51]. (a) Elastic phase. (b) Plastic phase. (c) Fiber failure segment. (d) Layer failure segment.

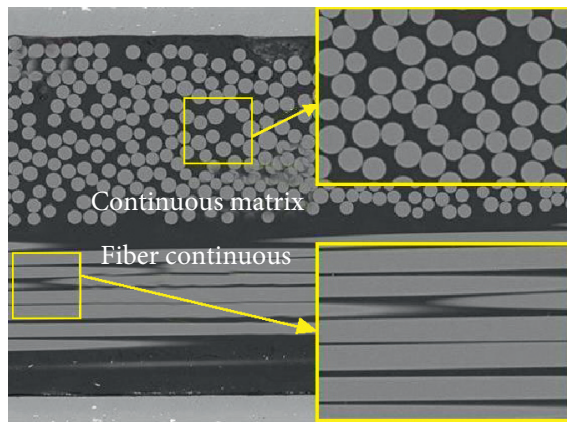

(a)

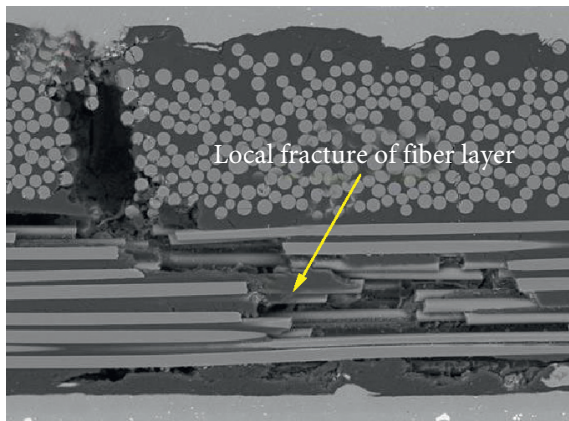

(c)

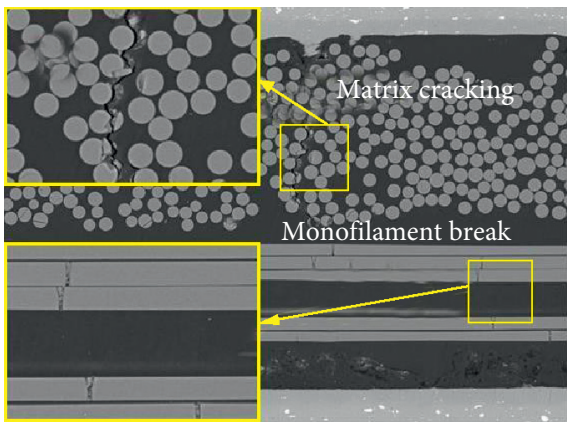

(b)

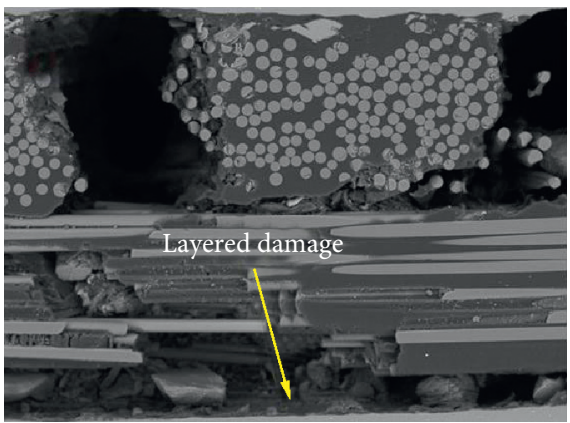

(d)

FIGURE 14: Microstructure of each stage of cross-ply laminates bending test observed by SEM (FEI Quanta 200) [51]. (a) Elastic phase. (b) Plastic phase. (c) Fiber failure segment. (d) Layer failure segment.

FMLs are issues of great concern, which interact with each other and ultimately lead to material failure.

There are many factors affecting the debonding and delamination of materials, including interlaminar shear stress, different properties, stress type, stress increment, and bonding strength of different material interfaces. FMLs with insufficient rigidity and poor interlaminar shear strength are easy to buckle and lose stability when subjected to shear 


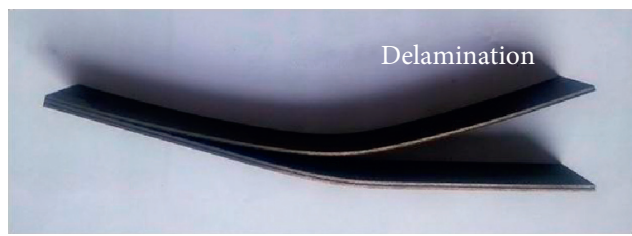

(a)

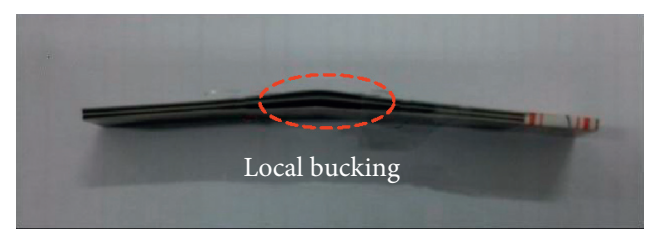

(b)

FIGURE 15: Ti/CF/PMR polyimide superhybrid laminate bending failure mode [56]. (a) Delamination failure; (b) local buckling failure.

stress. The extrusion-shear failure mode occurs under small span, resulting in debonding and delamination at multiple interfaces [51]. In the study of GLARE laminates, Liu [51] found that when the GLARE laminate had a span ratio of 8 , an effective interlaminar shear failure mode occurred, which was manifested in the local shear debonding of the metal layer and the fiber layer, as shown in Figure 16.

Jingming et al. [118] obtained that if the FML was laterally subjected to torsion, local debonding may occur, which led to delamination experimentally. It was found that the fiber layer could not effectively transfer the load to the underlying aluminum alloy when subjected to axial compression; it would result in cracks and eventually lead to debonding and delamination.

For FMLs, interfacial debonding and fiber pull-out occur simultaneously, as shown in Figure 17. The failure process starts with the occurrence of cracks in the metal matrix, and then the cracks propagate until the debonding failure occurs. From the beginning of the metal matrix cracking, the composite material can continue to bear part of the additional load because the load has not yet reached the critical strength of the fiber-metal interface. When the applied stress reaches the critical value, the interface near the matrix crack will debond with the increase of the crack size of the metal matrix. In the process of continuous loading, the interlaminar crack is continuously widened, the fiber deformation is intensified along length direction, and the fiber will be gradually pulled out. In essence, the process of interfacial debonding is always accompanied by interface slip and crack growth [119].

Interlaminar delamination is a typical failure mode of FMLs, which is caused by normal peeling stress and low shear strength of the materials. The interlaminar damage of FMLs is often accompanied by delamination damage. Once delamination damage occurs, the structural stiffness and strength will be greatly reduced; in particular the compressive strength will be significantly reduced [50]. Common factors causing delamination of FMLs are shown in Table 2.

Among them, Ye et al. [121] studied the effect of temperature and humidity on the strength of composite materials. A microscopic mechanical model was developed to investigate the failure of composite structures subjected to coupled thermomechanical condition, which provided microscopic stress distribution of the material under the coupled thermomechanical loading for failure analysis. It showed that a higher ambient temperature variation would generally cause stiffness degradation for laminates. Compared with the macromechanical method, they found that microscopic mechanical model can reveal the physical mechanisms of deformation for the composites [122].
Some scholars have also studied the ultimate stress at the notch of FMLs and the form of interlaminar failure. To observe the damage initiation at the notch corner in hybrid FMLs, a $90 \%$ of effective stress of the failure strength was applied on the notched samples. At this stress, the surface aluminum layers and glass fibers remained intact, while multiple cracks of boron fibers took place in the hybrid FMLs. However, the X-ray radiography images of the delamination zone in notched samples showed some differences. As shown in Figure 18, dark zone represented the delamination region between the composite and aluminum layers. In order to validate the result of $\mathrm{X}$-ray radiography, the aluminum layers of fractured samples were chemically removed. Figure 19 presents images of the delamination profile of notched samples after removal of the aluminum layers and revealed the transverse direction of failure propagation. It was also found that the notch sizes not only influenced the strength but also affected the delamination sizes on the samples [123].

Researchers found that when the crack of the metal layer of the FML expanded, there was no crack growth in the prepreg layer [124]. Therefore, while the prepreg hinders the growth of the tip crack by the bonding, part of the load that the metal layer should be carried in the main crack region is transferred to the prepreg layer. The transferred load is called the bridging stress. Bridging stress causes shear deformation between the metal layer and the prepreg layer, resulting in delamination. Due to the great difference between the properties of the fiber layer and the metal layer, the interlaminar property is easy to be affected, resulting in delamination damage between the layers and causing structural damage and failure during the manufacturing and using process [50].

\section{Development Trend of FMLs}

At present, FMLs have been extensively researched and developed. However, in the material preparation process, the failure behavior caused by factors such as processing technology, forming methods, and surface treatment can be avoided or reduced to some extent. Therefore, there are still many optimizations that need to be discussed.

New constitutive models of FMLs under complex conditions are in need to improve the reliability and efficiency of the research. A new research presented a modeling technique based on a biphasic decomposition of the composite material into idealized fiber and matrix phases, which can describe different types of matrix damage with a unique constitutive law. The objective of the approach is to model the damage mechanisms in the matrix within the same 


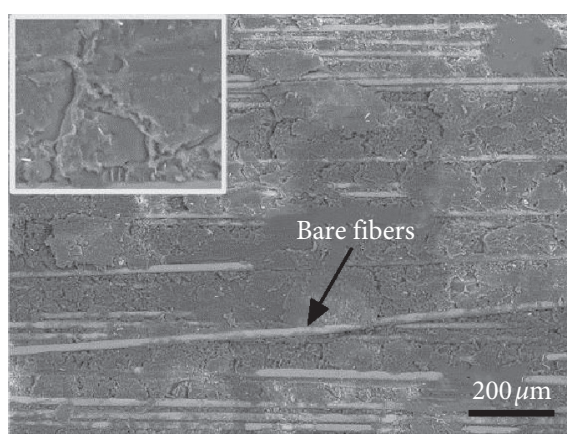

(a)

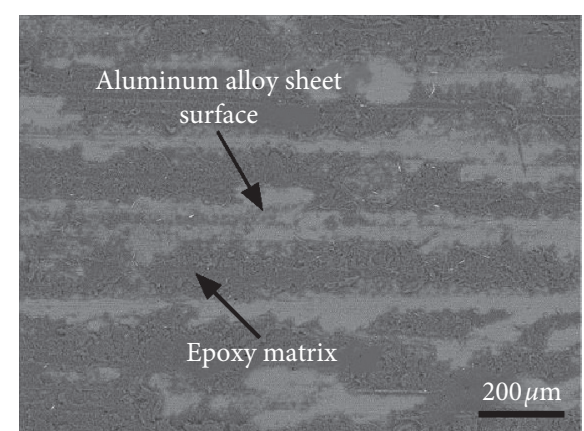

(b)

FIGURE 16: Micromorphology of interlaminar shear debonding surface, observed by SEM (FEI Quanta 200) [51]. (a) Composite material layer shear surface; (b) aluminum alloy layer shear surface.

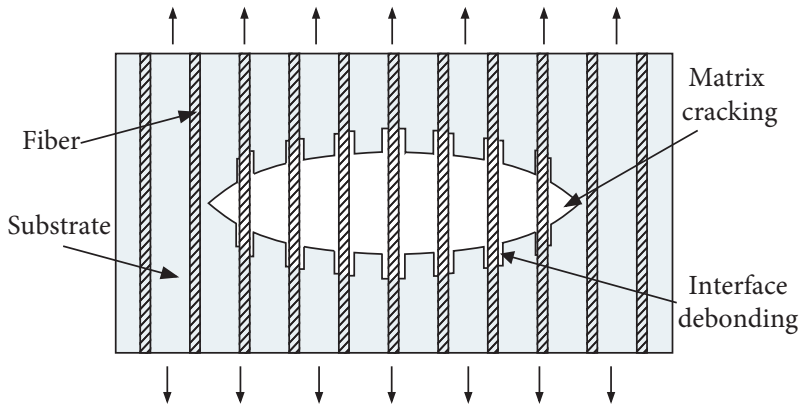

Figure 17: Mechanism of interfacial debonding and matrix cracking of fiber reinforced resin matrix composites [120].

element by using a single constitutive law [25]. A research group [125] found that multiscale method, including the microscopic scale [126], the laminar scale, and the structural scale, could be used to capture internal cracks and reveal damage evolutions of the material from microscopic damage to macroscopic fracture. It was concluded that the multiscale modeling strategy could be used to predict some mechanical properties of composite structures in an effective way [127].

More accurate testing methods are in need to obtain the mechanical properties of FMLs and predict the service behavior more accurately. A new experimental investigation was designed to determine the impact of thermal shocks on the mechanism of composite destruction in the three-point SBS test. The damage characteristics were observed by SEM to assess failure modes. It was found that both the failure mode and interlaminar shear strength depended on the number of thermal shock cycles. Under the influence of cyclic temperature changes in the test samples, the observed reduction in the strength of the layer subjected to thermal shocks is mainly caused by significantly different values of thermal expansion of the composite materials [46]. Due to the complicated loading conditions of impact and fatigue failure, the current research in this area mainly focuses on the dynamic response research under low-velocity impact $[12,110,128,129]$, but there are few detailed simulation models for analysis, and there are few studies on the impact of high-velocity impact on material properties $[24,85]$. This requires scholars to thoroughly study the mechanical behavior of materials under two- dimensional and three-dimensional stress conditions and further improve the establishment of three-dimensional damage models of composite materials.

The service environment of the FMLs varies a lot in many industries; researchers need to highly restore the service conditions in order to obtain more accurate experimental results. For example, after exposure to ultraviolet or humid air, the chemical composition of the surface of the material may change, thereby greatly reducing the life of the material $[14,130-132]$. Therefore, it is suggested that the influence of environmental factors on FMLs in future research work should be studied.

It is urgent to improve the interlaminar bonding quality, because the interlaminar properties of FMLs are related to the bonding quality of the material interface. Many scholars have begun to realize that the addition of some chemical substances in a certain volume fraction, such as the addition of multiwalled carbon nanotubes and clay, can effectively improve the interlaminar properties, interlaminar fracture toughness, and bending property of FMLs $[60,133,134]$. In the further research, researchers need to find out the substances that can be added and their corresponding improvements in certain aspects of laminate properties.

The advanced forming methods of FMLs also have a significant impact on their interlaminar failure behavior. In particular, there are certain problems in the formation of curved parts. In order to overcome the failure behavior of fiber layer and metal layer cracking, new forming methods have appeared in recent years, including hot forming process, creep-curing composite forming methods, high speed forming methods, and self-resistance heating forming methods [135]. A granted patent of China in this respect has been proposed by the authors: an integrated preparation method of curing/ forming/heat treatment for curved surface parts of carbon fiber aluminum alloy laminates (ZL201811101687.2) [136]. Using double-sided hot gas forming technology, the FMLs can be deformed and cured simultaneously with high mechanical properties and low springback. However, the research on the above new methods is still not mature enough, and further research and optimization are needed.

Selecting a matrix material with excellent property, safety, and environmental protection is more conducive to 
TABLE 2: Common factors causing delamination damage of FMLs.

\begin{tabular}{|c|c|}
\hline Origin & Common types \\
\hline Manufacturing process & $\begin{array}{c}\text { Residual stress during manufacturing } \\
\text { Machining (such as drilling) } \\
\text { Hot and humid environment } \\
\text { Low-velocity impact } \\
\text { Out-of-plane load }\end{array}$ \\
\hline Material and structural discontinuity in the design & $\begin{array}{c}\text { Free edges } \\
\text { Openings } \\
\text { The skin-web connection position } \\
\text { Structural corners } \\
\text { Sudden changes in layer thickness } \\
\text { Switching position of solid material/sandwich material }\end{array}$ \\
\hline
\end{tabular}

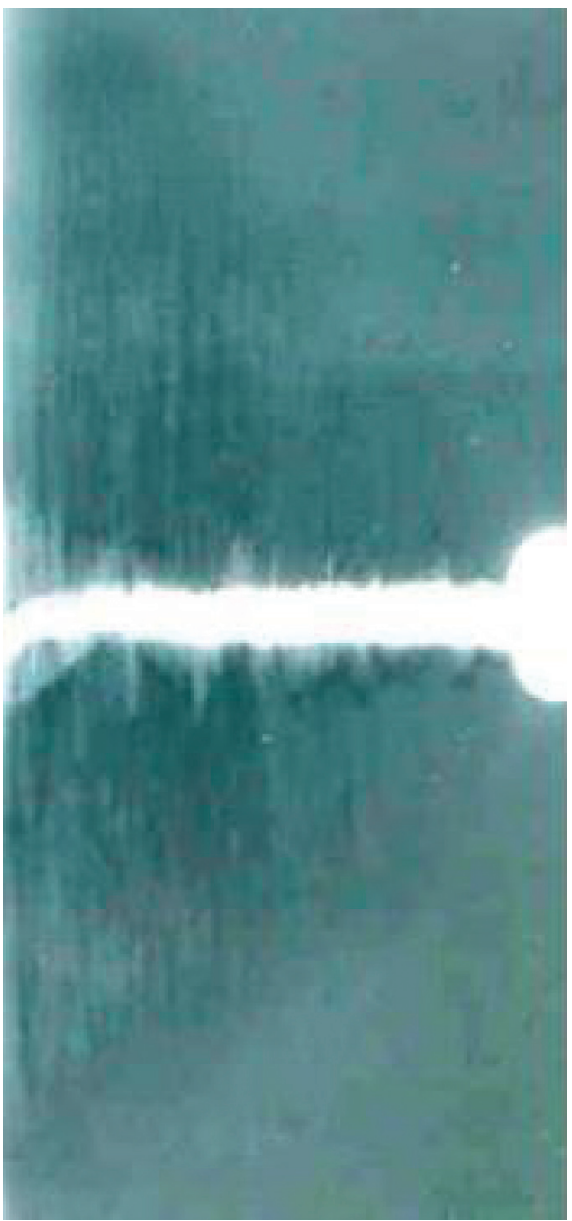

(a)

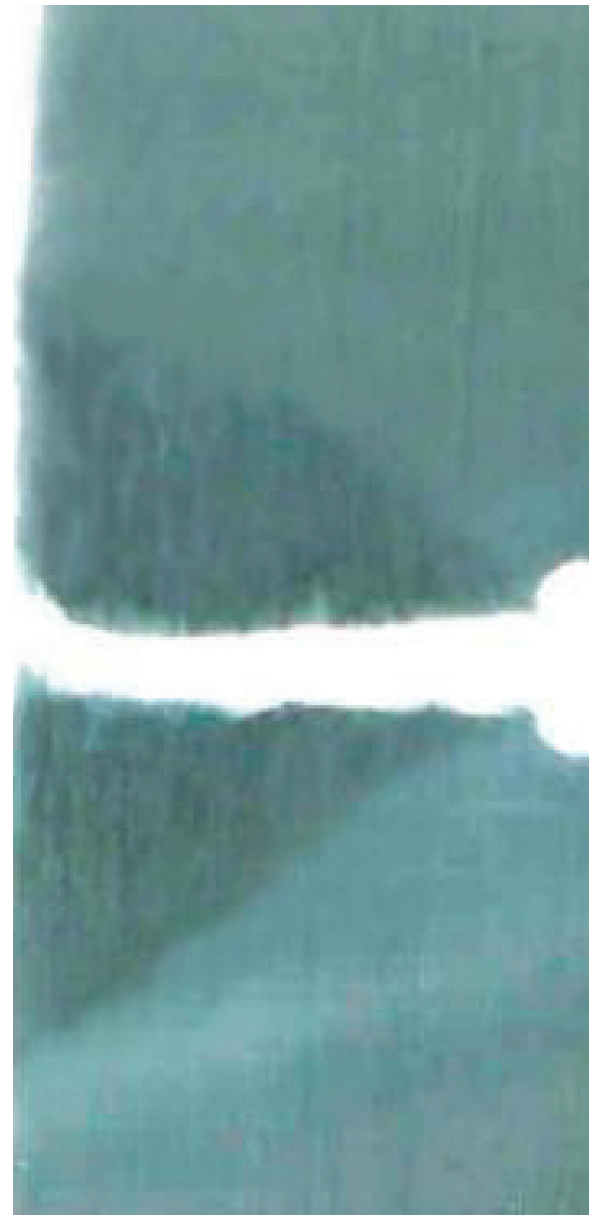

(b)

FIGURE 18: X-ray images of the damage zone in samples with $1 / 8$ in. Notch diameter of (a) type I hybrid FMLs and (b) type II hybrid FMLs $[123]$.

achieving energy conservation and environmental protection. Thermoplastic FMLs have higher toughness and good impact resistance and are recyclable [23, 24, 137]. From the current research, there are few studies on the tensile property and fatigue property of the surface-treated thermoplastic FMLs. The related research on the influence of fiber content and fiber braiding structure on the performance of thermoplastic FMLs is also obviously insufficient. It is believed that comprehensive research on the mechanical properties of thermoplastic FMLs will have higher value in the future.

Through continuous exploration in recent years, it has been discovered that FMLs have achieved unprecedented development. As the FML can meet the characteristics of high strength and light weight at the same time, it will be widely used in the field of transportation in the future. At the same time, some more accurate modeling methods and 


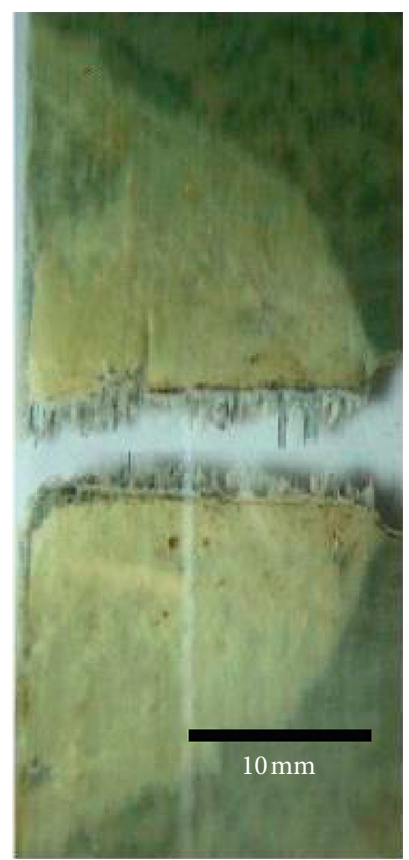

(a)

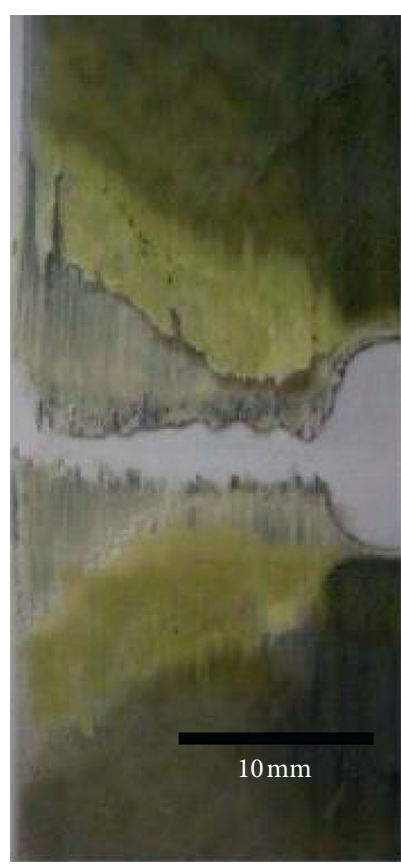

(b)

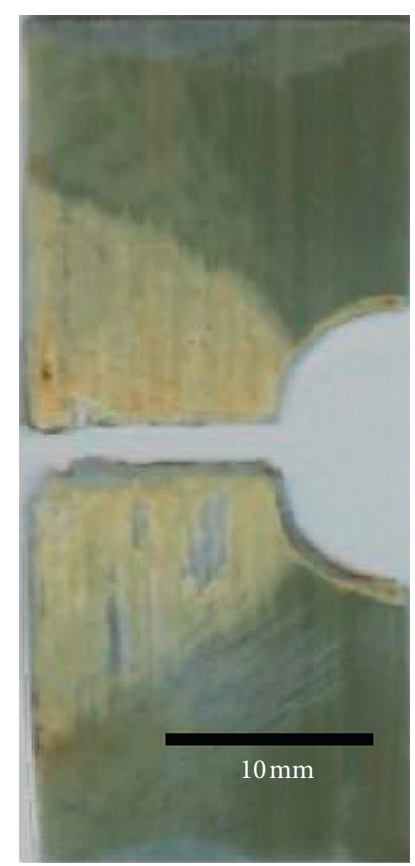

(c)

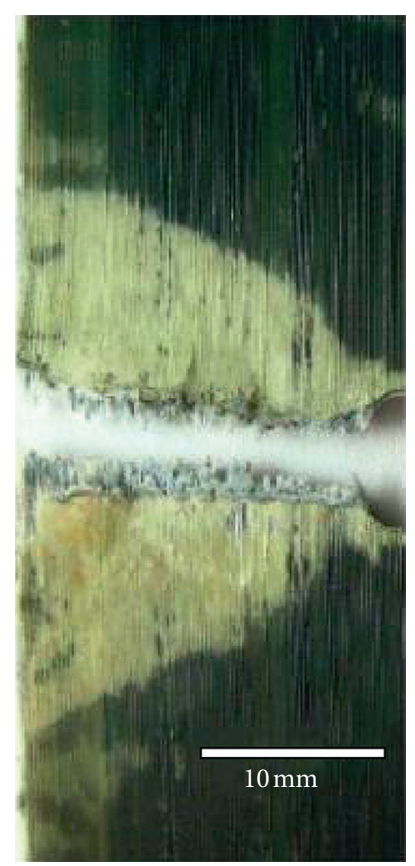

(d)

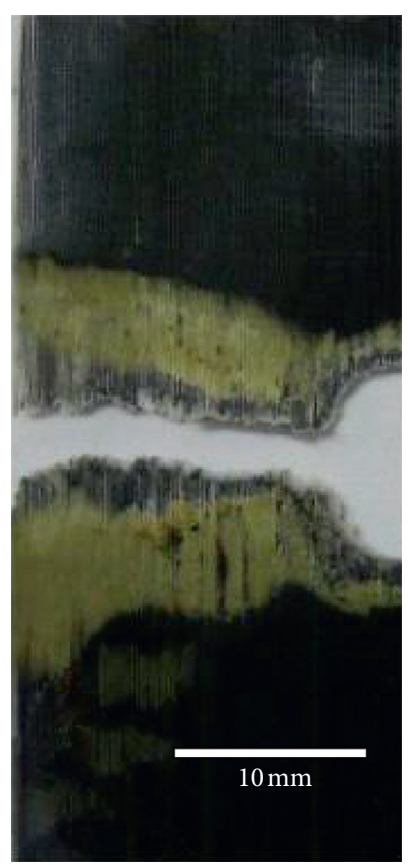

(e)

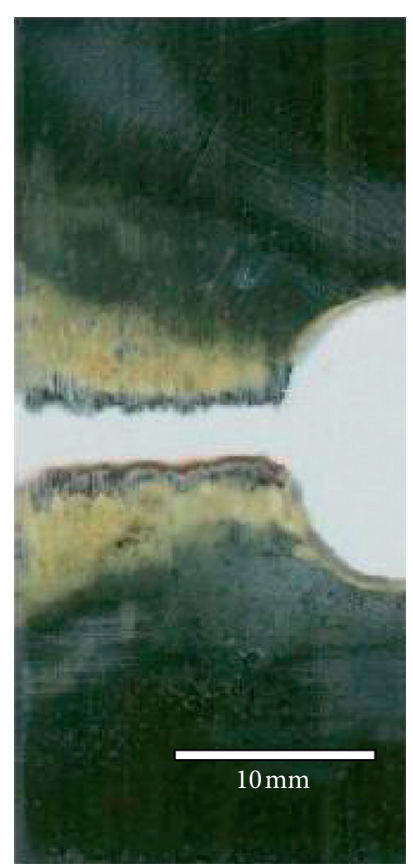

(f)

FiguRe 19: Images of delamination profiles after chemical removal of aluminum layers of type I hybrid FMLs with notch size of (a) $D=1 / 8$ in., (b) $D=1 / 4$ in., and (c) $D=1 / 2$ in. and type II hybrid FMLs with notch size of (d) $D=1 / 8$ in., (e) $D=1 / 4$ in., and (f) $D=1 / 2$ in. [123].

comprehensive enhancement methods need to be integrated and applied. It is believed that, after conducting a more comprehensive study, the interlaminar failure behavior of FMLs can be effectively controlled.

\section{Conclusion}

This review paper is a collection of various researches done by many groups. The main conclusions are as follows:
(1) The application status of several common fiber metal laminates (FMLs) in aircraft structures was given. At present, FMLs are mainly used as large aircraft structural materials, including aircraft skins, wings and tails, fairings, cabin floors, upper fuselage panels, and upper wall girders. The types of FMLs used in the aerospace field are mainly aramid fiber reinforced aluminum alloy laminates (ARALL) and glass reinforced aluminum laminates (GLARE). TIGR 
laminates have also been widely used in large civil aircraft in Europe.

(2) The common interlaminar failure modes of FMLs were stated. Under pure shear stress, the failure behaviors that are likely to occur in the metal layer and the fiber layer are shear misalignment, end opening, or partial shear debonding, and so forth. Under bending stress, interlaminar shear failure or resin matrix crack failure and mixed failure may occur. Under axial stress, the laminate will have a variety of complex interlaminar and intraply failure modes, such as resin matrix cracking, fiber breakage, and fiber/resin interlaminar delamination and peeling. Under impact stress, metal layer cracking, fiber layer breakage, and interfacial debonding may occur. Among them, the interfacial debonding generally includes debonding between different fiber layers and between the fiber layer and the metal layer.

(3) The testing and evaluation methods of interlaminar properties were stated. The short-beam method (SBS) can be used to evaluate interlaminar shear property and interlaminar fracture toughness, including the three-point bending and four-point bending SBS. The SBS is simple to operate and saves material. The three-point bending SBS is also a good method for testing bending property. The cantilever method can be used to evaluate the interlaminar fracture toughness, including the single-cantilever method and the double-cantilever method. Cantilever method is simple and versatile. There is also a new method for evaluating the interlaminar bonding strength between fibers and the matrix in fiber composites-the fiber bundle composite test method. This method is also convenient to test and the test results are more concentrated.

(4) The failure mechanisms and the corresponding control methods were analyzed. Due to the anisotropy of the material (such as the difference in vertical and horizontal strength), when the FML is loaded in different directions, the property defects of the fiber or metal layer cause the FML to fail. Due to the lack of reinforcement in the thickness direction, the interlaminar property of the FML is much lower than its intraply property. The material properties of the fiber layer and the metal layer are quite different. Due to the great difference between the properties of the fiber layer and the metal layer, the interlaminar property is easy to be affected, resulting in delamination damage between the layers and causing structural damage and failure when subjected to external loads. In addition, the interlaminar failure of FMLs may be caused during the manufacturing process.

(5) In order to control the above defects, the metal surface treatment (including mechanical polishing and electrochemical corrosion) or the use of adhesives can effectively improve the adhesion between the layers. For different loading conditions, we can choose the appropriate ply angle to effectively control the failure behavior. It can also effectively change the property of the laminate by adjusting the volume fraction of the metal or fiber and then control the interlaminar failure of the FMLs.

\section{Conflicts of Interest}

The authors declare that they have no conflicts of interest.

\section{Acknowledgments}

The authors would like to acknowledge the financial support from the National Natural Science Foundation Council of China (Grants nos. 51805392 and 51775398), the 111 Project (Grant no. B17034), the Program for Innovative Research Team in University of Ministry of Education (Grant no. IRT_17R83), Natural Science Foundation of Hubei Province (Grant no. 2018CFB595), and the Fundamental Research Funds for the Central Universities (Grants nos. WUT: 2019IVB022, 2018III074GX, and 2018III067GX).

\section{References}

[1] M. Oppenoorth, Determining Primary Energy and CO2 Reduction Potentials of the German Residential Building Stock through Retrofit Application of Building Automation Systems, Utrecht University, Utrecht, Netherlands, 2016.

[2] G. Lorubio and P. Schlosser, "Euro mix: current European energy developments and policy alternatives for 2030 and beyond," IEEE Power and Energy Magazine, vol. 12, no. 2, pp. 65-74, 2014.

[3] M. Yang and X. Yu, "Energy efficiency to mitigate carbon emissions: strategies of China and the USA," Mitigation and Adaptation Strategies for Global Change, vol. 22, no. 1, pp. 1-14, 2017.

[4] D. Nestler, M. Trautmann, C. Zopp et al., "Continuous film stacking and thermoforming process for hybrid CFRP/aluminum laminates," Procedia CIRP, vol. 66, pp. 107-112, 2017.

[5] C. J. Lissenden, "Experimental investigation of initial and subsequent yield surfaces for laminated metal matrix composites," International Journal of Plasticity, vol. 26, no. 11, pp. 1606-1628, 2010.

[6] Z. Zuanxi, "Lightweight design of automobile drive shaft based on the characteristics of low amplitude load strengthening," Chinese Journal of Mechanical Engineering, vol. 24, no. 6, p. 1111, 2011.

[7] H. Bansemir and O. Haider, "Fibre composite structures for space applications-recent and future developments," Cryogenics, vol. 38, no. 1, pp. 51-59, 1998.

[8] G. Reyes and W. J. Cantwell, "The mechanical properties of fibre-metal laminates based on glass fibre reinforced polypropylene," Composites Science and Technology, vol. 60, no. 7, pp. 1085-1094, 2000.

[9] M. Thirukumaran, I. Siva, J. W. Jappes, and V. Manikandan, "Forming and drilling of fiber metal laminates-a review," Journal of Reinforced Plastics and Composites, vol. 37, no. 14, pp. 981-990, 2018.

[10] K. Dadej, J. Bieniaś, and B. Surowska, "Residual fatigue life of carbon fibre aluminium laminates," International Journal of Fatigue, vol. 100, pp. 94-104, 2017. 
[11] N. L. Feng, S. DharMalingam, K. A. Zakaria, and M. Z. Selamat, "Investigation on the fatigue life characteristic of kenaf/glass woven-ply reinforced metal sandwich materials," Journal of Sandwich Structures \& Materials, vol. 21, no. 7, pp. 2440-2455, 2018.

[12] B. Jaroslaw, S. Barbara, and J. Patryk, "The comparison of low-velocity impact resistance of aluminum/carbon and glass fiber metal laminates," Polymer Composites, vol. 37, no. 4, pp. 1056-1063, 2016.

[13] C. Bellini, V. Di Cocco, F. Iacoviello, and L. Sorrentino, "Performance evaluation of CFRP/Al fibre metal laminates with different structural characteristics," Composite Structures, vol. 225, Article ID 111117, 2019.

[14] K. Majerski, B. Surowska, and J. Bienias, "The comparison of effects of hygrothermal conditioning on mechanical properties of fibre metal laminates and fibre reinforced polymers," Composites Part B: Engineering, vol. 142, pp. 108-116, 2018.

[15] F. Sarasini, J. Tirillò, L. Ferrante et al., "Effect of temperature and fiber type on impact behavior of thermoplastic fiber metal laminates," Composite Structures, vol. 223, Article ID 110961, 2019.

[16] C. Dong, Y. Wang, J. Zhou, H. Zhu, and S. Cheng, "Interfacial bond property of aramid fibers reinforced polymer matrix composites," Gongcheng Suliao Yingyong, vol. 40, pp. 73-76, 2012, in Chinese.

[17] G. Pincheira, C. Canales, C. Medina, E. Fernández, and P. Flores, "Influence of aramid fibers on the mechanical behavior of a hybrid carbon-aramid-reinforced epoxy composite," Proceedings of the Institution of Mechanical Engineers, Part L: Journal of Materials: Design and Applications, vol. 232, no. 1, pp. 58-66, 2018.

[18] C. A. J. R. Vermeeren, "An historic overview of the development of fibre metal laminates," Applied Composite Materials, vol. 10, no. 4/5, pp. 189-205, 2003.

[19] T. V. Nong, M. S. A. ElSayed, and C. Biseul, "Experimental optimization and static characterization of modified fiber metal laminates with integrated mechanical interlock bonding system for aerospace applications," Polymer Composites, vol. 40, no. 4, pp. 1510-1525, 2018.

[20] J. Mingyin, X. Ping, Y. Jian, and D. Yun, "Research on technology and equipment of long fiber reinforced thermoplastics composites," Engineering Plastics Application, vol. 38, pp. 83-86, 2010.

[21] M. Qingyu, G. Yizhuo, L. Liang, W. Shaokai, L. Min, and Z. Zuoguang, "Annealing effect on crystalline structure and mechanical properties in long glass fiber reinforced polyamide 66," Journal of Applied Polymer Science, vol. 134, no. 23,2017

[22] S. Goris and T. A. Osswald, "Progress on the characterization of the process-induced fiber microstructure of long glass fiber-reinforced thermoplastics," Plastics Engineering, vol. 73, no. 1, pp. 46-47, 2017.

[23] W. Chai, X. Liu, Y. Shan, X. Wan, and E. Jiang, "Research on simulation of the bending fatigue test of automotive wheel made of long glass fiber reinforced thermoplastic considering anisotropic property," Advances in Engineering Software, vol. 116, pp. 1-8, 2018.

[24] M. Shayan Asenjan, A. R. Sabet, and M. Nekoomanesh, "Long fiber thermoplastic composites under high-velocity impact: study of fiber length," Journal of Composite Materials, vol. 53, no. 3, pp. 353-360, 2018.

[25] A. Airoldi, C. Mirani, and L. Principito, "A bi-phasic modelling approach for interlaminar and intralaminar damage in the matrix of composite laminates," Composite Structures, vol. 234, Article ID 111747, 2020.

[26] G. Wu and J.-M. Yang, "The mechanical behavior of GLARE laminates for aircraft structures," JOM, vol. 57, no. 1, pp. 72-79, 2005.

[27] P. Cortes and W. J. Cantwell, "The tensile and fatigue properties of carbon fiber-reinforced PEEK-titanium fibermetal laminates," Journal Of Reinforced Plastics And Composites, vol. 23, no. 15, pp. 1615-1623, 2004.

[28] E. C. Botelho, R. A. Silva, L. C. Pardini, and M. C. Rezende, "A review on the development and properties of continuous fiber/epoxy/aluminum hybrid composites for aircraft structures," Materials Research, vol. 9, no. 3, pp. 247-256, 2006.

[29] J. W. G. A. Vlot, Fibre Metal Laminates, Kluwer Academic Publishers, London, UK, 2001.

[30] S. Y. Park, W. J. Choi, and H. S. Choi, “A comparative study on the properties of GLARE laminates cured by autoclave and autoclave consolidation followed by oven postcuring," The International Journal of Advanced Manufacturing Technology, vol. 49, no. 5-8, pp. 605-613, 2010.

[31] C. D. Rans, R. C. Alderliesten, and R. Benedictus, "Predicting the influence of temperature on fatigue crack propagation in fibre metal laminates," Engineering Fracture Mechanics, vol. 78, no. 10, pp. 2193-2201, 2011.

[32] D. Burianek and S. Spearing, "Fatigue damage in titaniumgraphite hybrid laminates," Composites Science and Technology, vol. 62, no. 5, pp. 607-617, 2002.

[33] B. Müller, M. Hagenbeek, and J. Sinke, "Thermal cycling of (heated) fibre metal laminates," Composite Structures, vol. 152, pp. 106-116, 2016.

[34] J. Gilbert Kaufman, "Properties of aluminum alloys; tensile, creep, and fatigue data at high and low temperatures," Scitech Book News, vol. 24, p. 305, 2000.

[35] V. V. Antipov, "Efficient aluminum-lithium alloys 1441 and layered hybrid composites based on it," Metallurgist, vol. 56, no. 5-6, pp. 342-346, 2012.

[36] M. Bair, "New 7E7 airplane to create novel design traditions," Journal of Failure Analysis and Prevention, vol. 3, pp. 12-13, 2003.

[37] H. F. Wu, L. L. Wu, W. J. Slagter, and J. L. Verolme, "Use of rule of mixtures and metal volume fraction for mechanical property predictions of fibre-reinforced aluminium laminates," Journal of Materials Science, vol. 29, no. 17, pp. 4583-4591, 1994.

[38] Z. Zengmin, "Study on the effect of surface pits on the surface of TA2/PEEK interface type I fracture toughness," Master thesis, Nanjing University of Aeronautics and Astronautics, Nanjing, China, 2017, in Chinese.

[39] B. Smith, "The boeing 777," Advanced Materials \& Processes, vol. 161, no. 9, pp. 41-44, 2003.

[40] H.-G. Li, J. Ling, Y.-W. Xu et al., "Effect of aging treatment on precipitation behavior and mechanical properties of a novel aluminum-lithium alloy," Acta Metallurgica Sinica (English Letters), vol. 28, no. 6, pp. 671-677, 2015.

[41] H. Li, Y. Hu, Y. Xu et al., "Reinforcement effects of aluminum-lithium alloy on the mechanical properties of novel fiber metal laminate," Composites Part B: Engineering, vol. 82, pp. 72-77, 2015.

[42] H. Li, Y. Hu, C. Liu, X. Zheng, H. Liu, and J. Tao, "The effect of thermal fatigue on the mechanical properties of the novel fiber metal laminates based on aluminum-lithium alloy," Composites Part A: Applied Science and Manufacturing, vol. 84, pp. 36-42, 2016. 
[43] J. Sinke, "Development of fibre metal laminates: concurrent multi-scale modeling and testing," Journal of Materials Science, vol. 41, no. 20, pp. 6777-6788, 2006.

[44] T. Sinmazçelik, M. Ö. Bora, and O. Çoban, "A review: fibre metal laminates, background, bonding types and applied test methods," Materials \& Design, vol. 32, no. 7, pp. 3671-3685, 2011.

[45] M. E. Mehr, H. Aghamohammadi, S. N. H. Abbandanak, G. R. Aghamirzadeh, R. Eslami-Farsani, and S. M. H. Siadati, "Effects of applying a combination of surface treatments on the mechanical behavior of basalt fiber metal laminates," International Journal of Adhesion and Adhesives, vol. 92, pp. 133-141, 2019.

[46] A. Kubit, T. Trzepiecinski, M. Klonica, M. Hebda, and M. Pytel, "The influence of temperature gradient thermal shock cycles on the interlaminar shear strength of fibre metal laminate composite determined by the short beam test," Composites PART B-Engineering, vol. 176, Article ID 107217, 2019.

[47] R. Rodi, R. Alderliesten, and R. Benedictus, An Experimental Approach to Investigate Detailed Failure Mechanisms in Fibre Metal Laminates, Springer, Berlin, Germany, 2009.

[48] H. Li, Y. Xu, X. Hua, C. Liu, and J. Tao, "Bending failure mechanism and flexural properties of GLARE laminates with different stacking sequences," Composite Structures, vol. 187, pp. 354-363, 2018.

[49] S. Hinz, T. Omoori, M. Hojo, and K. Schulte, "Damage characterisation of fibre metal laminates under interlaminar shear load," Composites Part A: Applied Science and Manufacturing, vol. 40, no. 6-7, pp. 925-931, 2009.

[50] C. M. Cepeda-Jiménez, R. C. Alderliesten, O. A. Ruano, and F. Carreño, "Damage tolerance assessment by bend and shear tests of two multilayer composites: glass fibre reinforced metal laminate and aluminium roll-bonded laminate," Composites Science and Technology, vol. 69, no. 3-4, pp. 343-348, 2009.

[51] C. Liu, "Study on interlaminar shear failure behavior and mechanism of GLARE laminates," Master thesis, Nanjing University of Aeronautics and Astronautics, Nanjing, China, 2017, in Chinese.

[52] D. H. Pahr, F. G. Rammerstorfer, P. Rosenkranz, K. Humer, and H. W. Weber, "A study of short-beam-shear and doublelap-shear specimens of glass fabric/epoxy composites," Composites Part B: Engineering, vol. 33, no. 2, pp. 125-132, 2002.

[53] C. K. H. Y. Cheng, "Influence of temperature on mechanical properties of Ti/Cf/PMR hybrid laminates," Machine Building \& Automation, vol. 46, no. 6, 2017.

[54] P. He, M. Huang, S. Fisher, C. Y. Yue, and J. Yang, "Effects of primer and annealing treatments on the shear strength between anodized Ti6Al4V and epoxy," International Journal of Adhesion and Adhesives, vol. 57, pp. 49-56, 2015.

[55] S. M. Goushegir, J. F. Dos Santos, and S. T. Amancio-Filho, "Influence of aluminum surface pre-treatments on the bonding mechanisms and mechanical performance of metalcomposite single-lap joints," Welding in the World, vol. 61, no. 6, pp. 1099-1115, 2017.

[56] Y. Xu, Preparation and properties of Ti/CF/PMR polyimide super hybrid laminates, Ph.D. thesis, Nanjing University of Aeronautics and Astronautics, Nanjing, China, 2017, in Chinese.

[57] G. R. Rajkumar, M. Krishna, H. N. Narasimhamurthy, Y. C. Keshavamurthy, and J. R. Nataraj, "Investigation of tensile and bending behavior of aluminum based hybrid fiber metal laminates," Procedia Materials Science, vol. 5, pp. 60-68, 2015.

[58] Y. Xu, "Research on bending properties and failure mechanism of GLARE laminates," Master thesis, Nanjing University of Aeronautics and Astronautics, Nanjing, China, 2017, in Chinese.

[59] S. W. Yurgartis and S. S. Sternstein, "A micrographic study of bending failure in five thermoplastic-carbon fibre composite laminates," Journal of Materials Science, vol. 23, no. 5, pp. 1861-1870, 1988.

[60] F. Bahari-Sambran, J. Meuchelboeck, E. Kazemi-Khasragh, R. Eslami-Farsani, and S. Arbab Chirani, "The effect of surface modified nanoclay on the interfacial and mechanical properties of basalt fiber metal laminates," Thin-Walled Structures, vol. 144, Article ID 106343, 2019.

[61] Y. Hu, Y. Zhang, X. Fu, G. Hao, and W. Jiang, "Mechanical properties of $\mathrm{Ti} / \mathrm{CF} / \mathrm{PMR}$ polyimide fiber metal laminates with various layup configurations," Composite Structures, vol. 229, Article ID 111408, 2019.

[62] Y. Xu, H. Li, Y. Shen, S. Liu, W. Wang, and J. Tao, "Improvement of adhesion performance between aluminum alloy sheet and epoxy based on anodizing technique," International Journal of Adhesion and Adhesives, vol. 70, pp. 74-80, 2017.

[63] R. Fedele, B. Raka, F. Hild, and S. Roux, "Identification of adhesive properties in GLARE assemblies using digital image correlation," Journal of the Mechanics and Physics of Solids, vol. 57, no. 7, pp. 1003-1016, 2009.

[64] R. Alderliesten, G. Campoli, and R. Benedictus, "Modelling cyclic shear deformation of fibre/epoxy layers in fibre metal laminates," Composites Science and Technology, vol. 67, no. 11-12, pp. 2545-2555, 2007.

[65] H. Li, Y. Hu, X. Fu, X. Zheng, H. Liu, and J. Tao, "Effect of adhesive quantity on failure behavior and mechanical properties of fiber metal laminates based on the aluminumlithium alloy," Composite Structures, vol. 152, pp. 687-692, 2016.

[66] Y. B. Hu, H. G. Li, L. Cai et al., "Preparation and properties of fibre-metal laminates based on carbon fibre reinforced PMR polyimide," Composites Part B: Engineering, vol. 69, pp. 587-591, 2015.

[67] S. M. R. Khalili, V. Daghigh, and R. Eslami Farsani, "Mechanical behavior of basalt fiber-reinforced and basalt fiber metal laminate composites under tensile and bending loads," Journal of Reinforced Plastics and Composites, vol. 30, no. 8, pp. 647-659, 2011.

[68] B.-E. Lee, E.-T. Park, J. Kim, B.-S. Kang, and W.-J. Song, "Analytical evaluation on uniaxial tensile deformation behavior of fiber metal laminate based on SRPP and its experimental confirmation," Composites Part B: Engineering, vol. 67, pp. 154-159, 2014.

[69] E. V. Karpov and A. G. Demeshkin, "Strain and fracture of glass-fiber laminate containing metal layers," Journal of Applied Mechanics and Technical Physics, vol. 59, no. 4, pp. 699-705, 2018.

[70] A. P. Sharma, S. H. Khan, and V. Parameswaran, "Experimental and numerical investigation on the uni-axial tensile response and failure of fiber metal laminates," Composites Part B: Engineering, vol. 125, pp. 259-274, 2017.

[71] R. J. Mania, Z. Kolakowski, J. Bienias, P. Jakubczak, and K. Majerski, "Comparative study of FML profiles buckling and postbuckling behaviour under axial loading," Composite Structures, vol. 134, pp. 216-225, 2015. 
[72] X. L. He, J. H. Yin, Z. Q. Yang, and H. W. Liu, "Damage mechanism analysis of carbon fiber composites under compressive load," Key Engineering Materials, vol. 775, pp. 36-42, 2018.

[73] B. Chengzheng, "Research on the method for predicting the tensile and compressive strength of civilian fiber metal wall panel under unidirectional load," Master thesis, Harbin University of Science and Technology, Harbin, China, 2018, in Chinese.

[74] Q. An, J. Chen, X. Cai, T. Peng, and M. Chen, “Thermal characteristics of unidirectional carbon fiber reinforced polymer laminates during orthogonal cutting," Journal of Reinforced Plastics and Composites, vol. 37, no. 13, pp. 905-916, 2018.

[75] O. A. Pawar, Y. S. Gaikhe, A. Tewari, R. Sundaram, and S. S. Joshi, "Analysis of hole quality in drilling GLARE fiber metal laminates," Composite Structures, vol. 123, pp. 350$365,2015$.

[76] A. Afaghi-Khatibi, G. Lawcock, L. Ye, and Y.-W. Mai, "On the fracture mechanical behaviour of fibre reinforced metal laminates (FRMLs)," Computer Methods in Applied Mechanics and Engineering, vol. 185, no. 2-4, pp. 173-190, 2000.

[77] A. Seyed Yaghoubi and B. Liaw, "Thickness influence on ballistic impact behaviors of GLARE 5 fiber-metal laminated beams: experimental and numerical studies," Composite Structures, vol. 94, no. 8, pp. 2585-2598, 2012.

[78] S. M. R. Khalili, M. Sharafi, R. Eslami-Farsani, and A. Saeedi, "Effect of thermal cycling on tensile properties of degraded FML to metal hybrid joints exposed to sea water," International Journal of Adhesion and Adhesives, vol. 79, pp. 95-101, 2017.

[79] M. Sadighi, R. C. Alderliesten, and R. Benedictus, "Impact resistance of fiber-metal laminates: a review," International Journal of Impact Engineering, vol. 49, pp. 77-90, 2012.

[80] G. B. Chai and P. Manikandan, "Low velocity impact response of fibre-metal laminates-a review," Composite Structures, vol. 107, pp. 363-381, 2014.

[81] P. Cortés and W. J. Cantwell, "Fracture properties of a fibermetal laminates based on magnesium alloy," Journal of Materials Science, vol. 39, no. 3, pp. 1081-1083, 2004.

[82] P. Cortés and W. J. Cantwell, "The prediction of tensile failure in titanium-based thermoplastic fibre-metal laminates," Composites Science and Technology, vol. 66, no. 13, pp. 2306-2316, 2006.

[83] X. Li, M. Y. Yahya, A. Bassiri Nia, Z. Wang, and G. Lu, "Dynamic failure of fibre-metal laminates under impact loading - experimental observations," Journal of Reinforced Plastics and Composites, vol. 35, no. 4, pp. 305-319, 2015.

[84] F. D. Morinière, R. C. Alderliesten, and R. Benedictus, "Modelling of impact damage and dynamics in fibre-metal laminates-a review," International Journal of Impact Engineering, vol. 67, pp. 27-38, 2014.

[85] Y. Chen, G. Liao, L. Ren, and X. Liu, "Damage tolerance of GLARE laminates subjected to high-velocity impact," Acta Aeronautica et Astronautica Sinica, vol. 39, pp. 126-137, 2018.

[86] C. Evci and M. Gülgeç, "An experimental investigation on the impact response of composite materials," International Journal of Impact Engineering, vol. 43, pp. 40-51, 2012.

[87] F. D. Morinière, R. C. Alderliesten, M. Sadighi, and R. Benedictus, "An integrated study on the low-velocity impact response of the GLARE fibre-metal laminate," Composite Structures, vol. 100, pp. 89-103, 2013.
[88] A. Seyed Yaghoubi, Y. Liu, and B. Liaw, "Stacking sequence and geometrical effects on low-velocity impact behaviors of GLARE 5 (3/2) fiber-metal laminates," Journal of Thermoplastic Composite Materials, vol. 25, no. 2, pp. 223-247, 2011.

[89] A. S. Yaghoubi and B. Liaw, "Experimental and numerical investigations of stacking sequence effect on GLARE 5 FML plates subjected to ballistic impact," in Proceedings of the ASME 2012 International Mechanical Engineering Congress and Exposition, Houston, Texas, USA, November 2012.

[90] H. G. Prashantha Kumar, S. Prabhakaran, M. Anthony Xavior et al., "Enhanced surface and mechanical properties of bioinspired nanolaminate graphene-aluminum alloy nanocomposites through laser shock processing for engineering applications," Materials Today Communications, vol. 16, pp. 81-89, 2018.

[91] J. J. C. Remmers and R. de Borst, "Delamination buckling of fibre-metal laminates," Composites Science and Technology, vol. 61, no. 15, pp. 2207-2213, 2001.

[92] G. Qi, S. Du, B. Zhang, and Y. Yu, "A new approach to assessing carbon fiber/epoxy interfacial shear strength by tensile test of $45^{\circ}$ fiber bundle composites: experiment, modeling and applicability," Composites Science and Technology, vol. 129, pp. 214-221, 2016.

[93] S. Y. Park, W. J. Choi, H. S. Choi, and H. Kwon, "Effects of surface pre-treatment and void content on GLARE laminate process characteristics," Journal of Materials Processing Technology, vol. 210, no. 8, pp. 1008-1016, 2010.

[94] E. C. Botelho, L. C. Pardini, and M. C. Rezende, "Evaluation of hygrothermal effects on the shear properties of Carall composites," Materials Science and Engineering: A, vol. 452453, pp. 292-301, 2007.

[95] C. Liu, D. Du, H. Li et al., "Interlaminar failure behavior of GLARE laminates under short-beam three-point-bending load," Composites Part B: Engineering, vol. 97, pp. 361-367, 2016.

[96] Y. Pan, G. Wu, Z. Huang, M. Li, S. Ji, and Z. Zhang, "Effect of surface roughness on interlaminar peel and shear strength of CFRP/Mg laminates," International Journal of Adhesion and Adhesives, vol. 79, pp. 1-7, 2017.

[97] Y. Pan, G. Wu, Z. Huang, M. Li, S. Ji, and Z. Zhang, "Effects of surface pre-treatments on mode I and mode II interlaminar strength of CFRP/Mg laminates," Surface and Coatings Technology, vol. 319, pp. 309-317, 2017.

[98] H. Ning, Y. Li, N. Hu et al., "Experimental and numerical study on the improvement of interlaminar mechanical properties of Al/CFRP laminates," Journal of Materials Processing Technology, vol. 216, pp. 79-88, 2015.

[99] M. Kanerva, L.-S. Johansson, J. M. Campbell et al., "Hydrofluoric-nitric-sulphuric-acid surface treatment of tungsten for carbon fibre-reinforced composite hybrids in space applications," Applied Surface Science, vol. 328, pp. 418-427, 2015.

[100] M. Shahverdi, A. P. Vassilopoulos, and T. Keller, "Modeling effects of asymmetry and fiber bridging on Mode I fracture behavior of bonded pultruded composite joints," Engineering Fracture Mechanics, vol. 99, pp. 335-348, 2013.

[101] C. Xu, T. Siegmund, and K. Ramani, "Rate-dependent crack growth in adhesives I. Modelingapproach," International Journal of Adhesion and Adhesives, vol. 23, no. 1, pp. 9-13, 2003.

[102] C. Xu, T. Siegmund, and K. Ramani, "Rate-dependent crack growth in adhesives II. Experiments and analysis," International Journal of Adhesion and Adhesives, vol. 23, no. 1, pp. 15-22, 2003. 
[103] X. Zhang, Q. Ma, Y. Dai et al., "Effects of surface treatments and bonding types on the interfacial behavior of fiber metal laminate based on magnesium alloy," Applied Surface Science, vol. 427, pp. 897-906, 2018.

[104] C. Ageorges, L. Ye, and M. Hou, "Experimental investigation of the resistance welding of thermoplastic-matrix composites. Part II: optimum processing window and mechanical performance," Composites Science and Technology, vol. 60, no. 8, pp. 1191-1202, 2000.

[105] A. Zhamu, W. H. Zhong, and J. J. Stone, "Experimental study on adhesion property of UHMWPE fiber/nano-epoxy by fiber bundle pull-out tests," Composites Science and Technology, vol. 66, no. 15, pp. 2736-2742, 2006.

[106] L. Qi, "Experimental study on interfacial properties of laminates using fiber bundle composites," Master thesis, South China University of Technology, Guangzhou, China, 2015, in Chinese.

[107] J. Fan, Z. W. Guan, and W. J. Cantwell, "Numerical modelling of perforation failure in fibre metal laminates subjected to low velocity impact loading," Composite Structures, vol. 93, no. 9, pp. 2430-2436, 2011.

[108] Q. Meng and Z. Wang, "Micromechanical modeling of impact damage mechanisms in unidirectional composite laminates," Applied Composite Materials, vol. 23, no. 6, pp. 1099-1116, 2016.

[109] Q. Sun, G. Zhou, H. Guo et al., "Failure mechanisms of crossply carbon fiber reinforced polymer laminates under longitudinal compression with experimental and computational analyses," Composites Part B: Engineering, vol. 167, pp. 147-160, 2019.

[110] J. Bienias, P. Jakubczak, and K. Dadej, "Low-velocity impact resistance of aluminium glass laminates-experimental and numerical investigation," Composite Structures, vol. 152, pp. 339-348, 2016.

[111] J. Zhang, Y. Wang, J. Zhang et al., "Characterizing the offaxis dependence of failure mechanism in notched fiber metal laminates," Composite Structures, vol. 185, pp. 148-160, 2018.

[112] C. Li, J. Xu, and M. Chen, "Effects of specialized drill bits on hole defects of CFRP laminates," in Proceedings of the AIP Conference, vol. 1960, Maharashtra, India, July 2018.

[113] M. Özgür Bora, O. Çoban, T. Sinmazçelik, and I. Cürgül, "The influence of different circular hole perforations on interlaminar shear strength of a novel fiber metal laminates," Polymer Composites, vol. 37, no. 3, pp. 963-973, 2016.

[114] M. Kawai and Y. Arai, "Off-axis notched strength of fiber-metal laminates and a formula for predicting anisotropic size effect," Composites Part A: Applied Science and Manufacturing, vol. 40, no. 12, pp. 1900-1910, 2009.

[115] J. Ye, C. Chu, H. Cai et al., "A multi-scale modeling scheme for damage analysis of composite structures based on the high-fidelity generalized method of cells," Composite Structures, vol. 206, pp. 42-53, 2018.

[116] H. Aghamohammadi, S. N. Hosseini Abbandanak, R. Eslami-Farsani, and S. M. H. Siadati, "Effects of various aluminum surface treatments on the basalt fiber metal laminates interlaminar adhesion," International Journal of Adhesion and Adhesives, vol. 84, pp. 184-193, 2018.

[117] H. L. Schreyer and A. Peffer, "Fiber pullout based on a onedimensional model of decohesion," Mechanics of Materials, vol. 32, no. 12 , pp. 821-836, 2000.

[118] T. Jingming, L. Huaguan, and L. Cheng, "Basic formability research and experimental test of glass fiber reinforced aluminium laminates," Journal of Aeronautical Materials, vol. 37, pp. 86-92, 2017.
[119] J. Bieniaś, P. Jakubczak, B. Surowska, and K. Dragan, "Lowenergy impact behaviour and damage characterization of carbon fibre reinforced polymer and aluminium hybrid laminates," Archives of Civil and Mechanical Engineering, vol. 15, no. 4, pp. 925-932, 2015.

[120] Q. Meng, "Meso-mechanical analysis of problems related to composite tensile/impact failure," Doctoral dissertation, Harbin Engineering University, Harbin, China, 2015, in Chinese.

[121] J. Ye, Y. Wang, Z. Li et al., "Failure analysis of fiber-reinforced composites subjected to coupled thermo-mechanical loading," Composite Structures, vol. 235, Article ID 111756, 2020.

[122] J. Ye, Y. Hong, H. Cai, Y. Wang, Z. Zhai, and B. Shi, “A new three-dimensional parametric FVDAM for investigating the effective elastic moduli of particle-reinforced composites with interphase," Mechanics of Advanced Materials and Structures, vol. 26, no. 22, pp. 1870-1880, 2019.

[123] P.-C. Yeh, P.-Y. Chang, J.-M. Yang, P. H. Wu, and M. C. Liu, "Blunt notch strength of hybrid boron/glass/aluminum fiber metal laminates," Materials Science and Engineering: A, vol. 528, no. 4-5, pp. 2164-2173, 2011.

[124] D. J. Shim, R. C. Alderliesten, S. M. Spearing, and D. A. Burianek, "Fatigue crack growth prediction in GLARE hybrid laminates," Composites Science and Technology, vol. 63, no. 12, pp. 1759-1767, 2003.

[125] J. Ye, C. Chu, H. Cai et al., "A multi-scale model for studying failure mechanisms of composite wind turbine blades," Composite Structures, vol. 212, pp. 220-229, 2019.

[126] J. Ye, Y. Wang, Y. Wang, B. Shi, Y. Li, and X. Qiao, "Microscopic modeling and effective properties evaluation of glass/epoxy plain woven composites," Materials Research Express, vol. 5, no. 10, Article ID 105303, 2018.

[127] Q. Meng, B. Li, T. Li, and X.-Q. Feng, "Effects of nanofiber orientations on the fracture toughness of cellulose nanopaper," Engineering Fracture Mechanics, vol. 194, pp. 350361, 2018.

[128] L. Yao, C. Wang, W. He, S. Lu, and D. Xie, "Influence of impactor shape on low-velocity impact behavior of fiber metal laminates combined numerical and experimental approaches," Thin-Walled Structures, vol. 145, Article ID 106399, 2019.

[129] Z. Wang and J. Zhao, "Low velocity impact response of GLARE laminates based on a new efficient implementation of Puck's criterion," Thin-Walled Structures, vol. 144, Article ID 106321, 2019.

[130] Y. Hu, H. Li, X. Fu, X. Zhang, J. Tao, and J. Xu, "Hygrothermal characterization of polyimide-titanium-based fibre metal laminate," Polymer Composites, vol. 39, no. 8, pp. 2819-2825, 2018.

[131] W. Zhao, Y. Huang, H. Song, and C. Huang, "Residual strength and damage mechanisms of laminated carbon fiber reinforced polymer under thermal environments and laser irradiations," Polymer Engineering \& Science, vol. 58, no. 12, pp. 2311-2319, 2018.

[132] F. Moleiro, E. Carrera, G. Li, M. Cinefra, and J. N. Reddy, "Hygro-thermo-mechanical modelling of multilayered plates: hybrid composite laminates, fibre metal laminates and sandwich plates," Composites Part B: Engineering, vol. 177, Article ID 107388, 2019.

[133] A. A. Khurram, R. Hussain, H. Afzal, A. Akram, and T. Subhanni, "Carbon nanotubes for enhanced interface of fiber metal laminate," International Journal of Adhesion and Adhesives, vol. 86, pp. 29-34, 2018. 
[134] K. Jin, H. Wang, J. Tao, and X. Zhang, "Interface strengthening mechanisms of Ti/CFRP fiber metal laminate after adding MWCNTs to resin matrix," Composites Part B: Engineering, vol. 171, pp. 254-263, 2019.

[135] J. Liu, J. Zhang, G. Yue, and Z. Ge, "Research on forming technology for curved parts of fiber metal laminate," Aviation Manufacturing Technology, vol. 62, pp. 46-52, 2019, in Chinese.

[136] Y. Chen, Z. Liu, H. Wang, Z. Hu, and L. Hua, Integrated Preparation Method for Solidifying/Forming/Heat-Treating Curved Parts of Carbon Fiber Metal Laminate, 2018.

[137] C. Zopp, A. Dittes, D. Nestler, I. Scharf, L. Kroll, and T. Lampke, "Quasi-static and fatigue bending behavior of a continuous fiber-reinforced thermoplastic/metal laminate," Composites Part B: Engineering, vol. 174, Article ID 107043, 2019. 